\title{
Hacia una jurisprudencia arbitral en el arbitraje internacional de inversiones*
}

\author{
Towards a doctrine of precedent in international \\ investment arbitration
}

Dolores Bentolila**

SUMARIO: I. Introducción. II. El uso del precedente arbitral en el arbitraje de inversiones. III. El resultado del uso del precedente arbitral en el arbitraje de inversiones. IV. Conclusión.

* Artículo recibido el 1o. de noviembre de 2010 y aceptado para su publicación el 29 de junio de 2011.

** Doctorante y asistente de enseñanza e investigación en el Graduate Institute of International and Development Studies, Ginebra. Miembro de la Sociedad Latinoamericana para el Derecho Internacional. 
RESUMEN: La jurisprudencia arbitral y el valor del precedente arbitral en el arbitraje de inversiones han generado un gran debate. El furor se debe a que en el arbitraje de inversiones si bien es relativamente nuevo, los laudos contienen innumerables citas de otros, a fin de imitarlos o rechazarlos por ser inaplicables o incorrectos. Ello ha dado lugar a una práctica donde el precedente arbitral es sistemáticamente usado por las partes para fundar sus pretensiones y el que absorbe una buena parte de las discusiones y de la motivación del laudo. De dicha práctica existen divergencias, pero también coherencias; modos consensuados acerca del modo de aplicar el derecho. Este artículo analiza estos conceptos y procura aclarar el rol y el funcionamiento de la jurisprudencia en el arbitraje internacional de inversiones.

Palabras clave: jurisprudencia arbitral, precedente arbitral, normas de origen arbitral, arbitraje internacional de inversiones.

ABSTRACT: The role of arbitral precedents in investment arbitration has generated considerable debate. This debate is due to the fact that in investment arbitration, though it is relatively new, arbitral awards contain numerous citations of others awards in order to imitate them or reject them as being irrelevant or wrong. This has resulted in a practice where arbitral precedents are systematically used by the parties to argue their claims and absorb much of the discussions and motivation of the award. This article discusses these concepts and seeks to clarify the role and functioning of arbitral law making in investment arbitration.

Descriptors: Arbitral Case Law, Stare Decisis, Arbitral Precedent, Arbitral Law-Making, International Investment Arbitration.

RÉSUMÉ: La jurisprudence arbitrale et le rôle du précédent arbitral ont suscités un grand débat. La polémique découle du fait que dans l'arbitrage d'investissement, bien que relativement récent, les sentences arbitrales contiennent de nombreuses références à d'autres sentences arbitrales pour imiter leurs décisions ou pour rejeter les critères précédemment suivis car ils ne sont pas pertinents ou corrects. Ainsi, une pratique a émergée dans l'arbitrage d'investissement, où le précédent arbitral est systématiquement utilisé par les parties pour fonder leurs prétentions et, par conséquent, absorbe une grande partie des discussions et de la motivation de la sentence. Cet article décrit ces concepts et cherche à clarifier le rôle et fonctionnement de la jurisprudence arbitrale dans l'arbitrage d'investissement.

Mots-Clés: Jurisprudence arbitrale, le précédent arbitral, les normes d'origine arbitral, l'arbitrage des investissements internationaux. 


\section{INTRODUCCIÓN}

Si bien en el arbitraje de inversiones no existe un sistema de stare decisis o de jurisprudencia obligatoria, los precedentes arbitrales y su línea consistente son invocados casi sistemáticamente por las partes, para defender sus posiciones, por los expertos legales, para darle contenido a normas jurídicas abstractas, y finalmente por los árbitros quienes los imitan o no en sus decisiones con base en derecho. Así, el precedente arbitral ha adquirido un rol importante en el arbitraje de inversiones, convirtiéndose en un lenguaje jurídico imprescindible en la solución de controversias. De dicha práctica surgió un diálogo entre tribunales independientes acerca del modo de interpretar y aplicar el derecho. De él resultan divergencias pero también coherencias, principios consensuados acerca del modo de resolver una generalidad de casos. Esta práctica ha generado un gran debate en doctrina y jurisprudencia acerca del valor, la existencia y el funcionamiento de una jurisprudencia en el arbitraje de inversiones.

\section{El concepto de jurisprudencia}

Existen dos acepciones del término jurisprudencia. En un sentido formal y amplio, es un fenómeno judicial; es lo que los tribunales hacen, un conjunto de decisiones judiciales. ${ }^{1}$ En un sentido material y restrictivo, es un método de creación de normas generales. ${ }^{2}$ Es esta segunda noción la que desarrollaré en este artículo.

En los sistemas jurídicos nacionales, aunque la misión de los jueces es la de resolver las controversias jurídicas que se le someten, éstos crean, en determinadas circunstancias, soluciones que producen efectos más allá de los casos que resuelven.

1 Diccionario de la Real Academia lo define como "Criterio sobre un problema jurídico establecido por una pluralidad de sentencias concordes", http://buscon.rae.es/drael/Srvlt Consulta?TIPO_BUS=3\&LEMA=jurisprudencia

2 Aguiló Regla, Teoría general de las fuentes del derecho: (y del orden jurídico), 2000, p. 116. 
En los países de common law, en virtud de la doctrina del stare decisis, las decisiones de tribunales superiores (como la House of Lords en Inglaterra o la Corte Suprema de Estados Unidos) son obligatorias para los tribunales inferiores y respecto de ellos mismos, salvo que sea irrazonable o inconveniente o que existan decisiones contradictorias de tribunales de la misma jerarquía. ${ }^{3}$ En tal sistema, el precedente constituye el método de creación de normas generales y es su fuente directa. La cuestión acerca de si los precedentes son fuentes de derecho o una mera declaración de normas consuetudinarias ha sido ampliamente debatida. Mientras que Coke y Blackstone consideraban los precedentes como declarativos, ${ }^{4}$ los realistas legales ${ }^{5}$ y los positivistas ${ }^{6}$ los consideraban como fuentes de derecho. Independientemente de este debate, la dificultad de rastrear la fuente consuetudinaria de los precedentes, junto con el hecho de que las costumbres y máximas en las que los precedentes se basan no están definidos como una norma escrita, permite una amplia discrecionalidad judicial. Dado que la determinación judicial sobre la existencia y el alcance de tal norma consuetudinaria forma parte de la ratio decidendi, ella es vinculante para otros tribunales. Por lo tanto, la decisión judicial se convierte en la norma misma.

En los países de derecho civil, si bien se basan en un sistema de derecho codificado, los tribunales superiores pueden, en ciertos casos, imponer una jurisprudencia constante. Ello es el caso en México respecto de 5 decisiones consecutivas de la Suprema Corte de Justicia en virtud de lo establecido por la ley de amparo $^{7}$ o de Guatemala respecto a 5 fallos consecutivos de la Corte Suprema de Justicia. ${ }^{8}$ Esta jurisprudencia es considerada fuente de derecho positivo y, por tanto, obligatoria

Sprecher, "The Development of the Doctrine of Stare Decisis and the Extent to Which It Should be Applied”, 31 ABAJ, 1945, 468, p. 502.

4 Wasserstrom, Judicial Decision Towards a Theory of Legal Justification, 1961, p. 41.

5 Gray, The Nature and Sources of the Law, 1921; Cardozo, The Nature of the Judicial Process, 1921; Holmes, The Common Law, 1991; Pound, The spirit of the common law, 1998; Ross, On law and justice, 2004, p. 76.

6 Bentham, Theory of legislation, 1908; Austin, The province of jurisprudence determined, 1861; Hart, The concept of law, 1994.

7 Artículo 192, de la Ley de Amparo, Reglamentario de los Artículos 103 y 107 de la Constitución Política de los Estados Unidos Mexicanos.

8 Código Procesal Civil y Mercantil de Guatemala, artículos 621-627. 
respecto de otros tribunales. En tales casos, el objeto de la solución judicial es, por lo general, una interpretación oficial de normas escritas. A diferencia del stare decisis, el método de creación de normas generales judiciales en estos sistemas es el de la "fuente-hecho" y no la "fuenteacto". En otras palabras, la norma general es creada por la repetición y la consistencia de la solución judicial. Asimismo, en estos sistemas también existe un método informal e impreciso que desarrollan los tribunales inferiores entre sí. Ello hace referencia a un conjunto coherente de soluciones resultantes de la imitación voluntaria. Estos mecanismos existen respecto de las decisiones de tribunales inferiores entre sí, las que si bien no tienen fuerza obligatoria, son imitadas, citadas y repetidas y de su sistematización surgen informalmente y de una manera un tanto imprecisa soluciones generales. ${ }^{9}$ El estatus de estas soluciones ha sido largamente discutido por la doctrina a través del tiempo. El debate tiene sus raíces en la división histórica entre dos visiones acerca de la función de los jueces: un verdadero jurisprudente — rival del monopolio de la legislatura - o un técnico que satisface los postulados de Montesquieu y la escuela de la exégesis, basada en el principio republicano de la división de poderes, en virtud del cual los jueces no crean derecho sino que lo aplican. ${ }^{10}$ Desde finales del siglo XIX, la doctrina ha ido reconociendo cada vez más el rol de la jurisprudencia en la creación del derecho. ${ }^{11}$ Este método de creación de normas generales es, sin embargo, diferente y más modesto que los métodos formales ya que no es obligatorio. Al contrario, proporciona al derecho flexibilidad y actualidad, ayudando a preservar la experiencia judicial pasada.

9 Zenati, La jurisprudence, Méthodes du droit, 1991, p. 177.

10 Para Montesquieu los jueces son la boca que pronuncia las letras de la ley, seres inanimados que no pueden moderar ni la fuerza ni el rigor de la ley Montesquieu, De l'esprit des lois, 1962, Chap. VI.

11 Zenati, La jurisprudence, op. cit.; Aguiló Regla, Teoría general de las fuentes del derecho: (y del orden jurídico); Puig Brutau et al., La jurisprudencia como fuente de derecho. Interpretación creadora y arbitrio judicial, 2a. ed., Edición Homenaje a D José Puig Brutau, 2006. Bonnecase, Introduction à l'étude du droit, 3a. ed., 1939, p. 125, §113; Planiol, Traité élémentaire du droit civil conforme au programme officiel de la faculté de droit, vol. 1, 1899; Geny, Méthode d'interprétation et sources en droit privé positif : essai critique, 2a. ed., vol. II, 1995, p. 2; Coste-Floret, Les problèmes fondamentaux du droit (1946), Chap. IV, 104. Tunc, "Jurisprudence”, 9 Encyclopaedia Universalis, p. 580 . 
La creación de normas generales por los jueces nacionales, ya sea a través de mecanismos formales o informales, parece ser un elemento esencial de la actividad judicial y su resultado natural. ¿Es ello el caso en arbitraje de inversiones?

\section{La especificidad del arbitraje de inversiones}

El arbitraje es un mecanismo de resolución de conflictos, de naturaleza privada, en virtud del cual dos o más partes confían la resolución de una disputa legal a uno o más particulares —árbitros - quienes emitirán una decisión definitiva y obligatoria para las partes. ${ }^{12}$ Esto implica que el arbitraje es consensual (contractual o no), ya que el consentimiento de las partes es la fuente de los poderes y de la misión del árbitro, y jurisdiccional, puesto que la función de los árbitros es la de emitir una decisión vinculante que ponga fin a una controversia jurídica. Esto significa que los árbitros, como los jueces, tienen la jurisdictio; es decir, el poder de decir el derecho, solucionando una controversia jurídica por medio de una decisión con fuerza de cosa juzgada. ${ }^{13}$ Dada esta igual función de los árbitros con la de los jueces, parece natural esperar que los laudos arbitrales creen, en determinadas circunstancias, normas generales; sin embargo, el arbitraje internacional es privado y autónomo, y los laudos arbitrales son definitivos y no están sujetos a ningún mecanismo institucionalizado de recurso que permita la coherencia de decisiones.

\section{A. Naturaleza privada y autónoma del arbitraje de inversiones}

A diferencia de los tribunales nacionales y los tribunales permanentes internacionales el arbitraje es privado. Los árbitros son personas particulares que derivan su misión y poderes del consentimiento de las partes y no de una delegación de la administración de justicia del Estado

12 David, L'arbitrage dans le commerce international, 1982, p. 9; Fouchard et al., On International Commercial Arbitration, 1999; Born, International Commercial Arbitration, 2009, p. 1; Redfern \& Hunter, Law and Practice of International Commercial Arbitration, 2004.

13 Clay, L'arbitre, Nouvelle Bibliothèque de Thèses, 2001, pp. 56-102. 
o de una comunidad de Estados. ${ }^{14}$ Los árbitros actúan a título privado y derivan su misión del consentimiento de las partes. Por esta razón, ellos no administran justicia en nombre de un Estado o de la comunidad internacional, no ponen en práctica el servicio público de la justicia y no manifiestan el ejercicio de la soberanía. ${ }^{15}$

La asimilación del arbitraje internacional a un órgano sujeto al ordenamiento jurídico en el que éste se lleva a cabo fue defendida por F. A. Mann en un artículo publicado en 1967 llamado Lex Facit Arbitum. ${ }^{16}$ Este autor declaró la fuerte similitud entre el juez nacional y el árbitro ya que ambos están sujetos a los soberanos locales. ${ }^{17}$ Para esta teoría, la ley de la sede (lex arbitri) sería la única fuente legal del arbitraje, regulando el procedimiento arbitral y el derecho aplicable al fondo (incluida la validez de la elección). Así, los laudos no serían internacionales pero ingleses, españoles o franceses, dado que el arbitraje tiene lugar en Inglaterra, España o Francia. La teoría ha sido muy criticada. Piénsese en las dificultades prácticas que su determinación puede producir en los casos en los que la sede arbitral no ha sido designada, existen varias sedes arbitrales (porque los árbitros se reunieron sucesivamente en varios países) o no hay ninguno en absoluto (porque el arbitraje se realizó por correo). ${ }^{18}$ Por otro lado, la sede del arbitraje podría tener un vínculo muy débil con el arbitraje, el que generalmente es elegido por conveniencia personal o por su neutralidad. Finalmente, un tribunal no se haya sujeto a la ley del Estado — a su derecho procesal y derecho internacional privado - porque no se encuentra localizado geográficamente en él. ${ }^{19} \mathrm{Al}$ mismo tiempo, el tribunal arbitral carece de imperio y necesita de los tribunales nacionales para ejecutar el laudo. En la mayoría de los casos, ello se rige por la Convención sobre el Reconocimiento y la Ejecución de las Sentencias Arbitrales Extranjeras de 1958 (Convención

14 Ibidem, pp. 200-202.

15 Idem.

16 Mann, "Lex Facit Arbitrum", International Arbitration Liber Amicorum for Martin Domke, 1986, p. 157.

17 Ibidem, p. 162.

18 Goldman, "Les conflits de lois dans l'arbitrage international de droit privé", 109 RCADI, 1963, 17, p. 372.

19 Ibidem, p. 375. 
de Nueva York). En ella se establecen las condiciones en las que cada Estado se compromete a reconocer en su territorio los laudos emitidos en otros países. Aunque se refiere a sentencias arbitrales "extranjeras" y no "internacionales", reduce considerablemente el papel de la sede convirtiéndose en subsidiaria a la autonomía de las partes (artículo V § $1, a, d) .{ }^{20}$ Además, el artículo VII de la Convención permite a los Estados ser más liberales en el reconocimiento de los laudos. Esto ha dado lugar a interpretaciones y aplicaciones muy diversas entre tribunales de diferentes países y a que en algunos países, como Francia, el consentimiento arbitral se controle en virtud de normas materiales y no de la sede. ${ }^{21}$ Asimismo, estas decisiones tienen efecto relativo. Por un lado, los exequátur no están destinados a producir efectos extraterritoriales y la ejecución podría ser concedida en un país y denegada en otro. Por otro lado, la anulación en el país de la sede, aunque incluida como causal para denegar el reconocimiento de un laudo en la Convención de Nueva York, no es sistemáticamente reconocida en otros Estados. ${ }^{22}$ Esto ha llevado a algunos autores a concebir el arbitraje internacional como difuso y distribuido ya que cada uno de estos países tiene un título al reconocer el laudo según su propia ley. ${ }^{23}$

20 Gaillard, Aspects philosophiques du droit de l'arbitrage international, 2008, p. 53.

21 Cass. Civ. 1ère « Dalico », 20 décembre 1993

22 En Francia (Cour de cassation, 1re civ., 23 mars 1994, Société Hilmarton Ltd. v. Société Omnium de traitement et de valorisation (OTV), JDI, 1994, p. 701, spéc. p. 702; Cour d'appel de Paris, 14 janvier 1997, République arabe d'Egypte v. Société Chromalloy Aero Services, JDI, 1998, p.750. En Estados Unidos, aún si en Chromalloy se rechazó la ejecución del laudo ya que éste había sido anulado en la sede del arbitraje, la tendencia es mas restrictiva después de Baker Marine, Spier y TermoRio. Chromalloy Aeroservices v. Arab Republic of Egypt, 31 juillet 1996, 939 F. Supp. 907 (DDC 1996); Rev. arb., 1997, p. 439; Baker Marine (Nig.) Ltd v. Chevron (Nig.) Ltd, 12 août 1999, 191 F. 3d 194 (2d cir. 1999); Rev. arb., 2000, p. 135, note E. Gaillard; Spier v. Calzaturificio Tecnica, S.p.A., 22 octobre 1999, 71 F. Supp. 2d 279 (SDNY 1999).; TermoRio S.A. E.S.P. et al. v. Electrificadora Del Atlantico S.A. E.S.P. et al., 17 mars 2006, 421 F. Supp. 2d 87; Rev. arb., 2006, p. 786, note J. Paulsson; Cour d'appel du district de Columbia, TermoRio S.A. E.S.P. et LeaseCo Group LLC v. Electranta S.P. et al., 25 mai 2007, 487 F. 3d 928; Rev. arb., 2007, p. 553, note J. Paulsson).

23 Von Mehren, "Limitations to Party Choice of the Governing Law: Do They Exist for International Commercial Arbitration?", The Mortimer and Raymond Sackler Institute of Advanced Studies, 1986, pp. 19 y 20; Mayer, "The Trend Towards Delocalisation in the Last 100 years", The Internationalisation of International Arbitration, The LCIA Centenary Conference, 1995, p. 46. 
Respecto de los arbitrajes de inversiones, se ha argumentado que, a diferencia de los arbitrajes comerciales internacionales, el tribunal arbitral es una jurisdicción internacional. ${ }^{24}$ El árbitro decidiría, entonces, en nombre de la comunidad internacional y el derecho internacional público sería la lex fori del árbitro o el orden jurídico en nombre del cual éste decide. La tesis ha sido criticada. ${ }^{25}$ El hecho de que el consentimiento de la parte estatal esté manifestado en un tratado internacional y que el derecho internacional se aplique a las reclamaciones basadas en un tratado no hace del árbitro una jurisdicción internacional. En primer lugar, el marco legal aplicable a dicho arbitraje incluye, además de las disposiciones expresas de los tratados de inversión, las normas de procedimiento elegidas por las partes (tales como las Reglas de Arbitraje de la Comisión de las Naciones Unidas para el Derecho Mercantil, CNUDMI) y el derecho interno del Estado de la sede del arbitraje. En segundo lugar, un laudo arbitral en el arbitraje de inversiones no es un laudo arbitral de derecho internacional público ya que está sujeto al régimen de ejecución y anulación de laudos comerciales internacionales y, por tanto, al control de tribunales estatales en virtud de sus propias concepciones. Como explica Zachary Douglas, un laudo o una decisión verdaderamente internacional, tal como un fallo de la Corte Internacional de Justicia (CIJ), debe su existencia y fuerza vinculante al orden jurídico internacional y es indiferente a cualquier recurso ante un tribunal nacional. Sólo un tribunal internacional es competente para conocer de las reclamaciones relativas a la validez de un laudo arbitral verdaderamente internacional, tal como la CIJ. ${ }^{26}$

En un punto aparte, es necesario referirse a la naturaleza sui generis de los arbitrajes realizados en el marco del Convenio sobre Arreglo de Diferencias Relativas a Inversiones entre Estados y Nacionales de otros Estados (Convenio del CIADI). Estos arbitrajes no están sometidos a la ley de la sede ni al régimen de la Convención de Nueva York, sino al

24 Leben, "Quelques réflexions théoriques à propos des contrats d'Etat”, Souveraineté étatique et marchés internationaux à la fin du 20ème siècle, A propos de 30 ans de recherche du CREDIMI, Mélanges en l'honneur de Philippe Kahn, 2000.

25 Douglas, "The Hybrid Foundations of Investment Treaty Arbitration", 74 BYIL, 2004, 151, p. 152 .

26 Douglas, The International Law of Investment Claims, 2009, p. 101. 
Convenio mismo, el que prevé su propio régimen arbitral y reglas especiales en materia de ejecución y anulación. Como explica Zachary Douglas, normalmente se asume que la lex arbitri en los arbitrajes CIADI es el derecho internacional. ¿Pero qué quiere decir esto?, ¿se supone, por ejemplo, que el derecho consuetudinario internacional en materia de admisibilidad de reclamos debe completar el Convenio del CIADI y el Reglamento de Arbitraje? Zachary Douglas responde a estas preguntas en forma negativa. Las normas internacionales en materia de admisibilidad de reclamos, tales como respecto de la nacionalidad o del agotamiento de recursos internos que se desarrollaron en el contexto de la protección diplomática no se pueden importar al arbitraje CIADI. ${ }^{27}$ El Convenio del CIADI más que confirmar esta opinión, corrobora el carácter autónomo o sui generis de los tribunales CIADI. Así, en cuestiones procesales, el artículo 44 del Convenio del CIADI establece que los procedimientos de arbitraje se realizarán de conformidad con el Convenio y el Reglamento, y que cualquier cuestión procesal no prevista por éstos será resuelta por el Tribunal. En cuanto a la competencia arbitral y el tipo de controversias que este Convenio cubre, éstas no se limitan a reclamaciones fundadas en tratados, sino también en contratos y leyes nacionales. De hecho, según el informe de los directores del Banco Mundial, el Convenio fue redactado principalmente para arbitrajes contractuales y eventualmente fundados en una oferta unilateral, como en una ley (omitiendo toda referencia a tratados). ${ }^{28}$ Finalmente, respecto del derecho aplicable al fondo, el artículo 42(1) del Convenio del CIADI, establece que en caso de que las partes no elijan el derecho aplicable, el tribunal aplicará tanto el derecho del Estado receptor como el derecho internacional. La relación entre dichos órdenes jurídicos ha sido largamente debatida por los tribunales arbitrales. Mientras que originariamente fue interpretada como una relación subsidiaria y jerárquica, donde el derecho internacional se aplica en caso de laguna o conflicto; ${ }^{29}$ desde la aparición del arbitraje basado en tratados, los tribu-

27 Douglas, “The Hybrid Foundations of Investment Treaty Arbitration”, cit., p. 152.

28 Stern, "Le consentement à l'arbitrage CIRDI en matière d'investissement international: que disent les travaux préparatoires”, Mélanges Ph KAHN, pp. 223 y ss.

${ }^{29}$ Klöckner Industrie-Amlagen GmbH, Klöckner Belge, S.A., Klöckner Handelsmaatschappij BV c. Camerún, Decisión del comité de anulación, Caso CIADI No. ARB/81/2 (en adelante: Klöc- 
nales la han concebido como una relación entre iguales, en la que cada derecho rige materias diferentes. ${ }^{30}$ Como explica Mathias Forteau, ${ }^{31}$ un tribunal arbitral CIADI aprehende el derecho nacional e internacional desde el exterior, sin entrar dentro de la perspectiva de uno de los dos ordenamientos jurídicos, ni de un tercer orden que regule la relación desde arriba. Su enfoque, y es lo que le da su originalidad, hace caso omiso de este punto (central para el pensamiento dualista para el cual el razonamiento jurídico no tiene sentido desde un orden jurídico dado). Un tribunal arbitral CIADI piensa en términos de derecho aplicable, no de órdenes jurídicos. Por tales motivos, el árbitro no decide en nombre del derecho internacional ni el arbitraje se desarrolla exclusivamente bajo su imperio.

En estas circunstancias, ¿cómo pueden los árbitros crear normas generales?, ¿en nombre de quién las crean?, ¿qué valores o concepciones defienden? El hecho que el árbitro sea autónomo respecto de los órdenes jurídicos nacionales y el orden jurídico internacional no impide a los árbitros tener en cuenta otros intereses que los de las partes, tales como los intereses de una comunidad más amplia. ¿Por qué el árbitro no podría tener en cuenta los intereses que se consideran legítimos respecto de cualquier individuo?32 Un ejemplo categórico es el del orden público transnacional o verdaderamente internacional. Si bien, la noción tuvo su origen en el arbitraje comercial, el concepto se extendió al arbitraje de inversiones a fin de declarar como inadmisibles los reclamos basados en inversiones ilegales, como aquellas tachadas de corrupción.

kner I Anulación) §69; Amco Asia y otros c. Indonesia, Decisión del comité de anulación, Caso CIADI No. ARB/81/1, 22 (en adelante: Amco Asia Anulación).

30 Wena Hotels Limited c. Egipto, Decisión del comité de anulación, Caso CIADI núm. ARB/98/4, 41 I.L.M. 896, 2002 (en adelante: Wena Hotels Anulación), p. 911; CMS Gas Transmission Company c. Argentina, Decisión del comité de anulación, Caso CIADI núm. ARB/01/8 (en adelante: CMS Anulación) §115; LG\&E Energy Corp., LG\&E Capital Corp., LG\&E International Inc. c. Argentina, Caso CIADI núm. ARB/02/1, Laudo del 3 octubre 2006 (en adelante: LG\&E Laudo).

31 Forteau, "Le juge CIRDI envisagé du point de vue de son office : juge interne, juge international, ou l'un et l'autre à la fois?", Liber Amicorum Jean-Pierre Cot, Le procès international, 2009, 95, pp. 113 y 114.

32 Mayer, "La règle morale dans l'arbitrage international", Etudes offertes à Pierre Bellet, 1991, p. 394; Gaillard, Aspects philosophiques du droit de l'arbitrage international, cit. p. 63. 
Precisamente, el caso World Duty Free c. Kenia, el tribunal rechazó la admisibilidad de un reclamo basado en una inversión corrupta ya que:

La corrupción es contraria al orden público internacional de la mayoría, sino de todos los Estados o, para usar otra fórmula, al orden público transnacional. Por lo tanto, las reclamaciones basadas en contratos corruptos o en contratos obtenidos por medio de corrupción no pueden ser admitidas por este Tribunal de Arbitraje. ${ }^{33}$

Este orden público transnacional, se refiere a un conjunto de principios (de diversas fuentes) ${ }^{34}$ que protegen valores superiores y que, en virtud de su universalidad, gozan de una superioridad intrínseca. Ello demuestra que a pesar de que el árbitro es de naturaleza privada y no decide en nombre de un orden jurídico, puede tener en cuenta intereses más generales y participar de la creación de una jurisprudencia basada en valores y principios compartidos; sin embargo, los laudos arbitrales son definitivos y el arbitraje internacional no se encuentra dentro de un marco institucional que permita la unificación de decisiones.

B. El carácter definitivo de los laudos y la falta de jerarquías institucionales

En segundo lugar, los laudos son definitivos y no están sujetos a un recurso de apelación que permita unificar decisiones. El único control es aquel realizado por los tribunales nacionales, respecto de los arbitrajes realizados fuera del ejido del CIADI, y por los comités ad hoc del CIADI, respecto de los arbitrajes CIADI. Estos mecanismos, en general, se limitan a garantizar la integridad e imparcialidad de la decisión y no a si la determinación de los hechos o la aplicación del derecho a los hechos es correcta. ${ }^{35}$ Un gran número de legislaciones nacionales y la Convención de Nueva York limitan el alcance de la revisión a la validez del

33 World Duty Free Company Ltd c. Kenya, Laudo del 25 de septiembre de 2006, Case CIADI No. $\mathrm{ARB} / 00 / 7, \S 157$ (en adelante: World Duty Free).

34 Las fuentes citadas por el tribunal arbitral en World Duty Free, incluyen convenciones internacionales, informes de asociaciones privadas, leyes y jurisprudencia nacionales y la jurisprudencia arbitral. Ibidem, §138-141.

35 Walsh, "Substantive Review of ICSID Awards: Is the Desire for Accuracy Sufficient to Compromise Finality”, 24 Berkeley Journal of International Law, 2006, p. 41. 
convenio arbitral, la constitución del tribunal arbitral, la observancia de garantías procesales mínimas y, la no contradicción con el orden público internacional. ${ }^{36}$ Además, el tribunal de anulación no re decide el caso sino que confirma o anula el laudo (borrando el efecto de cosa juzgada y poniendo a las partes en la situación en la que se encontraban antes del arbitraje). Por esta razón, el arbitraje no dispone de una estructura institucional que permita unificar decisiones y una jurisprudencia.

En el marco del CIADI, la situación es similar. El Convenio del CIADI establece un régimen autónomo que prevé un mecanismo de anulación ante comités ad hoc (artículo 52). Este control es también muy limitado y los comités no tienen, en principio, el poder de revisar el fondo o si la aplicación del derecho es correcta $;{ }^{37}$ sin embargo, algunos tribunales han visto en los comités ad hoc un rol para la unificación de laudos arbitrales. En AES c. Argentina, después de dar valor ilustrativo a los precedentes arbitrales, el tribunal declaró que los comités de anulación pueden constituir un factor para el desarrollo de una jurisprudencia constante arbitral. En las palabras del tribunal:

Difícilmente se puede negar que la dimensión institucional de los mecanismos de control previstos en el Convenio del CIADI puedan ser un factor, en el largo plazo, para contribuir a la elaboración de una doctrina legal común o de una jurisprudencia constante que resuelva algunas cuestiones jurídicas difíciles discutidas en muchos casos. ${ }^{38}$

No obstante, los comités de anulación del CIADI no pueden revisar si la decisión es correcta y justa. ${ }^{39}$ Por lo tanto, es difícil ver cómo

36 Artículos V de la Convención de Nueva York y 34 (2) de la Ley modelo de la CNUDMI sobre de Arbitraje Comercial.

37 Los motivos de anulación de un laudo según el artículo 52 del Convenio CIADI son “(a) que el Tribunal se hubiere constituido incorrectamente; (b) que el Tribunal se hubiere extralimitado manifiestamente en sus facultades; (c) que hubiere habido corrupción de algún miembro del Tribunal; (d) que hubiere quebrantamiento grave de una norma de procedimiento; o (e) que no se hubieren expresado en el laudo los motivos en que se funde".

38 AES Corporation c. Argentina, Caso CIADI No ARB/02/17, Decisión sobre jurisdicción del 26 de abril de 2005, 12 ICSID Rep. 308 (en adelante: AES c. Argentina Jurisdicción), §33

39 Sin embargo, esto ha sido interpretado en el tiempo de manera diferente, y algunos comités ad hoc han interpretado el alcance de la revisión de un modo flexible, incluyendo 
sus decisiones pueden tener ese efecto unificador. Los propios comités, tales como en los casos MCI y Enron, han rechazado tal papel (aunque en este último, el tribunal interpretó que un error en la aplicación del artículo IX del TBI Estados Unidos-Argentina constituía una extralimitación manifiesta de las facultades del árbitro). ${ }^{40}$ Esto no significa, sin embargo, que los comités de anulación no participen de la creación de soluciones generales en materia de procedimientos de anulación. ${ }^{41}$

Dada la ausencia de una estructura institucional, algunos autores han considerado que la existencia de una jurisprudencia arbitral es una empresa teóricamente imposible. ${ }^{42}$ ¿Cómo se coordinarán las decisiones? ¿cómo pueden surgir decisiones coherentes? Como se explicará en las próximas líneas, hay ciertos elementos que pueden permitir cierta unificación. Estos elementos son la similitud entre tribunales arbitrales y controversias, y el hecho de que los laudos son públicos y motivados.

Si bien los tribunales arbitrales son independientes entre sí, existen elementos que les permiten desarrollarse como una unidad. ${ }^{43}$ La juridización del arbitraje en el siglo XX permitió que la experiencia de un tribunal sea útil respecto de otro. El arbitraje adquirió una homogenización procesal en virtud de ciertas convenciones internacionales, leyes tipo de arbitraje y de la creación de ciertas instituciones arbitrales y reglamentos de arbitraje. ${ }^{44}$ Respecto a la sustancia, dichos arbitrajes tienen

errores de derecho. Las decisiones que siguen esta postura incluyen: Klöckner I Anulación; Compañia de Aguas del Aconquija S.A. and Vivendi Universal S.A. c. Argentina, Decisión del comité de anulación, Caso CIADI núm. ARB/97/3 (en adelante: Vivendi I Anulación); Enron Corporation and Ponderosa Assets LP c. Argentina, Decisión del comité de anulación, Caso CIADI ARB/01/3, (en adelante: Enron Anulación); Sempra Energy International c. Argentina, Decisión del comité de anulación, Caso CIADI núm. ARB/02/16 (en adelante: Sempra Anulación).

40 MCI Power Group LC y New Turbine Inc c. Ecuador, Caso CIADI núm. ARB/03/6, Decisión del comité de anulación (en adelante: MCI Anulación) §24; Enron Anulación, §63-66; Bjorklund, “Investment Treaty Arbitral Decisions as Jurisprudence Constante”, p. 271.

${ }^{41}$ Enron Anulación, §66 y MCI Anulación, §24-25.

42 Kassis, L'autonomie de l'arbitrage commercial international, 2005.

43 Acerca del impacto que la especialización produce en la manera que vemos el mundo ver. Kuhn, The Structure of Scientific Revolutions, 1966, pp. 50 y 51.

44 Con las conferencias de la Haya de 1899 y 1907, la Convención de Nueva York de 1958, el Convenio del CIADI, así como la ley modelo de arbitraje y el reglamento de arbitraje de la CNUDMI y una serie de instituciones arbitrales como aquel de la Cámara de Comercio Internacional (CCI) y la Corte Permanente de Arbitraje. Véase Crawford, "Continuity and 
en común que se basan, en la mayoría de los casos, en TBI's, muchos de ellos redactados sobre la base de tratados tipo o modelo, lo que permite la existencia de cláusulas idénticas en tratados diferentes. ${ }^{45}$

Podría alegarse que aún con esta similitud entre tribunales y tratados a aplicar, es difícil esperar que los árbitros se sigan ya que ellos tienen distintas nacionalidades, distintas tradiciones jurídicas o inclusive distintas profesiones. En un tribunal permanente, los jueces son los mismos y resulta hasta lógico esperar que un juez sea coherente consigo mismo. ${ }^{46}$ No obstante, si bien el arbitraje es plural, el pluralismo se convierte en neutralismo cultural y el arbitraje se va convirtiendo en un híbrido con elementos de varias tradiciones legales, lo que le da una naturaleza plural y específica. ${ }^{47}$ Como explica Thomas Wälde, el arbitraje está poco determinado por las culturas específicas o tradiciones legales nacionales y las reglas del arbitraje tienden a expresar una síntesis o una cohabitación de ambos modelos (common y civil law). ${ }^{48}$ Asimismo, por lo general, los árbitros corresponden a una determinada profesión, a veces en virtud del propio Convenio CIADI, ${ }^{49}$ y a una determinada especialización profesional, el arbitraje internacional. Además, los árbitros y

Discontinuity in International Dispute Settlement: An Inaugural Lecture”, 1, (1) Journal of International Dispute Settlement, 2010, 3, p. 10.

45 Dichos tratados generalmente siguen una misma estructura la que prevé, el ámbito de aplicación, las condiciones de admisión de la inversión extrajera, estándares absolutos y relativos de protección, transferencias de dinero, condiciones operativas de la inversión, protección contra la expropiación y la desposesión, indemnización de daños y perjuicios y solución de controversias McNair, The Development of International Justice, 1954, p. 15; Salacuse, “Towards a Global Treaty on Foreign Investment: The Search for a Grand Bargain”, in Horn (ed.), Arbitrating Foreign Investment Disputes, 2004, 61.

46 Gerhardt, 'The Limited Path Dependency of Precedent', 7 U Pa J Const L (2004-2005) 903, p. 952.

47 Véase en este sentido Gaillard (ed.), Towards a uniform international arbitration law?:YAP Seminars, Paris, March 28, 2003 ; Geneva - March 26, 2004 iai series, 2004, pp. 1 y ss.

48 Wälde, "The Specific Nature of Investment Arbitration", in T. Wälde (ed.), Les aspects nouveaux du droit des investissements internationaux / New Aspects of International Investment Law, 2007, p. 52.

49 El artículo 14 (1) del Convenio del CIADI dispone que "Las personas designadas para figurar en las Listas deberán gozar de amplia consideración moral, tener reconocida competencia en el campo del Derecho, del comercio, de la industria o de las finanzas e inspirar plena confianza en su imparcialidad de juicio. La competencia en el campo del Derecho será circunstancia particularmente relevante para las personas designadas en la Lista de Árbitros”. 
los abogados de las partes (que en ocasiones realizan ambas funciones indistintamente) pertenecen, por lo general, a departamentos especializados de grandes estudios de abogados o académicos especializados en dicha rama. Ello permite hablar de una comunidad profesional en la que comparten la misma experiencia y se influyen entre sí. ${ }^{50}$ Por otra parte, la realidad es que el arbitraje está monopolizado por un grupo bastante homogéneo de árbitros integrado por abogados y académicos especializados pertenecientes a una elite reducida de proveniencia occidental. Como lo muestra el estudio de J. Commission, la mayoría de los casos se concentra en un porcentaje de los árbitros inscritos en la lista, los cuales tienen varias nominaciones. ${ }^{51}$

Asimismo, la publicidad de los laudos arbitrales permite la emergencia de una "experiencia común”. En el arbitraje de inversiones, los árbitros por lo general, tienen acceso a las decisiones de otros tribunales ya que un gran número de laudos son públicos. ${ }^{52} \mathrm{Si}$ bien, como en los arbitrajes comerciales, la publicación del laudo depende del consentimiento de las partes, ${ }^{53}$ las partes por lo general no se oponen ${ }^{54}$ y los centros de arbitraje, ${ }^{55}$ las revistas jurídicas especializadas, ${ }^{56}$ así como los abogados de las partes las publican. ${ }^{57}$

50 Commission, "Precedent in Investment Treaty Arbitration. A Citation Analysis of a Developing Jurisprudence”, 24, (2) Journal of International Arbitration, 2007, 129, p. 136.

51 Como el caso de Kaufmann-Kohler y Yves Fortier con mas de 10 nominaciones en los casos pendientes al 2006. Ibidem, p. 140.

52 El número de laudos (finales y parciales) se eleva a más de 300. Este es el numero de laudos publicados en la base de datos www.investmentclaims.com.

53 Véase artículos 48(5) del Convenio del CIADI y 48(4) del Reglamento de arbitraje del CIADI, al igual que el 34.5 del Reglamento de arbitraje de la CNUDMI.

54 Walde, "Confidential Awards as Precedent in Arbitration. Dynamics and Implication of Award Publication", en Gailllard, E. and Banifatemi, Y. (eds.), Precedent in International Arbitration, 2007, 113-135, p. 123.

55 Este es el caso del CIADI (http://icsid.worldbank.org/ICSID/Index.jsp) y de la CCI (Collection of ICC Awards, Recueil des sentences arbitrales de la ICC y Collection of Procedural Decisions in ICC Arbitration).

56 Por ejemplo: International Law Materials, International Law Reports, www.investmentclaims. com, naftaclaims.com, TDM, www.ita.law. uvic.ca, JDI, ICA Yearbook.

57 Quienes publican por reputación profesional. Walde, "Confidential Awards as Precedent in Arbitration. Dynamics and Implication of Award Publication”, cit., p. 122. 
Por último, aunque los laudos sean públicos, es necesario que ellos sean motivados. En el caso del CIADI, ello resulta una exigencia cuya violación califica como motivo de anulación en virtud del artículo 52(1) (e) del Convenio. En los arbitrajes fuera del CIADI, aunque la Convención de Nueva York no se pronuncia sobre la cuestión, el Convenio Europeo de 1961 sobre Arbitraje Comercial Internacional ${ }^{58}$ y el Reglamento de Arbitraje de la CNUDMI ${ }^{59}$ establecen una presunción del deber de motivación. En la práctica, los laudos son motivados, salvo limitadas excepciones.

En resumen, teniendo en cuenta que las controversias y los tribunales arbitrales son similares y que los laudos arbitrales son motivados y públicos, los árbitros tienen a su disposición decisiones anteriores sobre cuestiones similares a las que tienen que decidir. Claramente, esto no garantiza que los árbitros se sigan, pero las circunstancias permiten hacerlo; si lo hacen, entonces, la consistencia puede surgir en un ámbito de libertad y descentralización.

\section{EL USO DEL PRECEDENTE ARBITRAL}

EN EL ARBITRAJE DE INVERSIONES

\section{La cita de precedentes arbitrales}

Según un estudio realizado por Jeffrey Commission la media de citas de precedentes arbitrales en 2006 es de 11.25 por laudo de tribunales arbitrales CIADI, 7 por laudo de tribunales bajo las reglas del mecanismo suplementario del CIADI y 18.43 por laudo de tribunales fuera del ejido del CIADI, tales como tribunales ad hoc y administrados por instituciones arbitrales como la Cámara de Comercio de Estocolmo (SCC) o la Cámara de Comercio Internacional $(\mathrm{CCI}) \cdot{ }^{60}$ Dichos laudos contienen

58 El artículo 80. dispone: "Motivación de la sentencia arbitral. Se presumirá que las partes han convenido en el acuerdo o compromiso arbitral que el laudo deberá ser motivado".

59 El artículo 34(3) del Reglamento de arbitraje comercial de la CNUDMI dispone: "El tribunal arbitral expondrá las razones en las que se base el laudo, a menos que las partes hayan convenido en que no se dé ninguna razón”.

60 Commission, "Precedent", cit., p. 149. 
innumerables citas de otros a fin de justificar una decisión determinada o a fin de rechazarla por ser inaplicable o incorrecta. Ello ha generado un gran diálogo entre tribunales arbitrales acerca del modo de decidir casos similares.

Tal diálogo se manifiesta, en primer lugar, a través de la cita de precedentes arbitrales como medio de motivación de una determinada solución. Un ejemplo de ello es el caso Sempra c. Argentina donde el tribunal, refiriéndose a Goetz, Enron y CMS (donde los tribunales habían admitido los reclamos de accionistas minoritarios), declaró:

Este Tribunal no tiene razones para apartarse de esa conclusión, aún cuando los elementos de hecho de cada controversia puedan tener algunas diferencias. Si el propósito del Tratado y los términos de sus disposiciones tienen la amplitud con que fueron negociados y aceptados no podrían ellos, como se ha señalado, ser desconocidos por el Tribunal pues privarían al Tratado de todo efecto útil. ${ }^{61}$

Por otro lado, el diálogo se manifiesta en un debate respecto de aquellas cuestiones controvertidas. Esto último se ilustra con el debate producido respecto de la cláusula paraguas, en el que los tribunales, si bien divergiendo, se esforzaron por referirse a las decisiones precedentes a fin de distinguirlas con el caso en cuestión o de rechazarlas. Así, por ejemplo, en SGS c. Filipinas, a pesar de que el tribunal había decidido adoptar una interpretación de la cláusula paraguas más amplia que aquella adoptada en SGS c. Pakistán, dedicó una buena parte del laudo para explicar por qué no compartía la solución adoptada en este último. Es interesante subrayar que el tribunal se esmeró en sacar a la luz los motivos de tal divergencia dedicando un par de párrafos del laudo para examinar la razón de ser de tal divergencia, analizando "las razones aducidas por el tribunal en SGS c. Pakistán para dar una interpretación tan restrictiva". ${ }^{62}$

${ }^{61}$ Sempra Energy International c. República Argentina, Caso CIADI No. ARB/02/16, Decisión sobre jurisdicción, 11 de mayo 2005, disponible en www.investmentclaims.com (visitado por última vez: 29 de marzo de 2010) (en adelante: Sempra Jurisdicción), §94.

62 SGS Société Générale de Surveillance S.A. c. Republica de Filipinas, Caso CIADI núm. ARB/02/6, Decisión sobre jurisdicción del 29 de enero de 2004; 8 ICSID Rep. 518 (2005), (en adelante: SGS c. Filipinas), §120-124. 
Asimismo, como se analiza a continuación, el precedente arbitral es también objeto de dicho diálogo entre tribunales, en el que se procurá definir el valor del precedente y justificar su uso.

\section{El valor del precedente arbitral para los árbitros}

En el arbitraje de inversiones los tribunales dan distinto valor a las decisiones arbitrales precedentes. De un análisis de los casos arbitrales en materia de inversiones de los últimos años, tanto CIADI como ad hoc, pueden extraerse dos grandes corrientes acerca del valor de la jurisprudencia arbitral. Para la primera, el árbitro tiene la facultad de citar precedentes. Para la segunda, el árbitro tiene el deber de desarrollar y respetar la jurisprudencia arbitral.

La primera postura es seguida, por ejemplo, en el caso AES c. Argentina, en la que el tribunal declaró que la misión limitada del árbitro no le impide seguir precedentes arbitrales, pero que ello no se les impone. ${ }^{63}$ En dicho caso, uno de los tantos iniciados contra Argentina debido a las medidas de emergencia adoptadas tras la crisis de 2001, Argentina alegaba que el tribunal no tenía jurisdicción ya que la diferencia no era entre AES y Argentina, sino entre las sociedades en las que AES participaba y Argentina. Argentina opuso entre otras excepciones, que la accionista no tenía ius standi para reclamar por los daños de la sociedad en la que participa y que la diferencia no tenía relación directa con la inversión. En contra de estas excepciones AES citó una serie de casos (Azurix, CMS, LG\&E, Enron y Siemens A.G. $)^{64}$ en los que los tribunales habían admitido las demandas de los accionistas por medidas dirigidas contra la sociedad local. Contra esta jurisprudencia, Argentina alegaba que dada la naturaleza especial de cada tratado y su carácter de lex specialis, el tribunal arbitral no puede seguir precedentes arbitrales ya que ello sería contrario al principio de consentimiento en que está basado el arbitraje. ${ }^{65} \mathrm{El}$ tribunal arbitral, declaró que estaba de acuerdo con Argentina en que

${ }^{63}$ AES c. Argentina Jurisdicción, $\$ 27$.

${ }^{64}$ http: / / www.investmentclaims.com/subscriber_article?script =yes\&id=/ic/Awards / law-iic-42005 \&recno $=1$ \&searchType $=$ Quick\&query $=$ AES - law-iic-4-2005-note-9.

65 AES c. Argentina Jurisdicción, §22-23. 
cada TBI tiene su identidad propia, que los precedentes arbitrales no son necesariamente relevantes para otros tribunales del CIADI y que Argentina tenía un derecho válido y legítimo de plantear las excepciones a la competencia que planteó infructuosamente en casos anteriores. ${ }^{66} \mathrm{No}$ obstante, el tribunal rechazó la afirmación excesiva que consistiría en pretender que, debido a la especificidad de cada caso, no puedan tenerse en cuenta decisiones anteriores. ${ }^{67}$ El tribunal continuó diciendo que si los casos y la base jurisdiccional de estos tribunales presentan un alto nivel de similitud o, aún más, una identidad, no está prohibido, como una cuestión de principio, considerar la posición expresada por estos otros tribunales. ${ }^{68}$ Dada la similitud entre los casos citados por la demandada, muchos compartían la base de competencia (el TBI entre Estados Unidos y Argentina y el Convenio del CIADI), el tribunal decidió seguir estos precedentes. El tribunal declaró, sin embargo, que a pesar de que existan similitudes entre los casos, las bases de competencia y las reglas aplicables, cada tribunal sigue siendo soberano y puede mantener una solución diferente para resolver un mismo problema. ${ }^{69}$

Por el contrario, para la segunda corriente el árbitro tiene el deber de seguir precedentes, en especial, las soluciones establecidas en una serie consistente de casos. Dicha posición resulta de un gran número de decisiones que han contado con el mismo presidente, tales como Austrian Airlines, Bayindir, Saipem y Burlington Resources. ${ }^{70}$ Todos ellos contienen un párrafo similar que luego del título: "La relevancia de otras decisiones u otros laudos arbitrales”, declara:

El tribunal considera que las decisiones de otros tribunales no son vinculantes. Al mismo tiempo, es de la opinión que debe considerar decisiones previas. El tribunal considera que, salvo motivos apremiantes en contrario, tiene el deber de adoptar las soluciones establecidas en una serie de casos consistentes. Asimismo, considera que, sujeto a las especificidades del tratado especifico y de las circunstancias del

${ }^{66}$ Ibidem, §24-26.

${ }^{67}$ Ibidem, $\$ 27$.

${ }^{68}$ Idem.

69 Ibidem, $§ 30$.

70 Burlington Resources c. Ecuador, §100; Austrian Airlines c. Eslovaquia, §84; Bayindir c. Pakistán; Saipem c. Bangladesh, §67. Todos ellos presididos por Gabrielle Kaufmann-Kohler. 
caso concreto, tiene el deber de contribuir al desarrollo harmonioso del derecho de las inversiones y, por tanto, de satisfacer las expectativas legitimas de la comunidad de estados y de inversores, en pos de la previsibilidad del estado de derecho. $^{71}$

Dicha posición es compartida por otros tribunales y comités de anulación del CIADI. En la anulación de MCI (lo que fue repetido por el comité de anulación en el caso Enron), ${ }^{72}$ luego de mencionar el rol limitado de los comités ad hoc, declaró que "la responsabilidad de asegurar consistencia en la jurisprudencia y de crear un cuerpo coherente de reglas reside principalmente en los tribunales de inversiones" y no en los comités de anulación. ${ }^{73}$

Aquí, la jurisprudencia, si bien se asume como persuasiva y no obligatoria, ya que el deber sería moral y no jurídico, ${ }^{74}$ desde un punto de vista operacional, se asimila a la jurisprudencia obligatoria, ya que en caso de ser constante, el árbitro debe seguirla salvo razones apremiantes en contrario. Por otra parte, desde el punto de vista de los objetivos y fines de la jurisprudencia, la jurisprudencia arbitral cumpliría las mismas funciones que la jurisprudencia obligatoria o la ley; esto es, previsibilidad y seguridad jurídica. ${ }^{75}$ No obstante, el árbitro tiene su poder con base en una convención específica, un acuerdo concreto para resolver una diferencia concreta y cuyo poder desaparece luego de emitida la decisión. Como se mencionó previamente el arbitro es privado y no representa un orden jurídico nacional o el orden jurídico internacional. Él no es su guardián y su misión no incluye la de desarrollar el orden jurídico que aplica respecto del cual tiene una relación de inmediatez. Como se mencionó supra, ello no impide al arbitro, sin embargo, tomar

71 Austrian Airlines c. Eslovaquia, $\$ 84$.

72 Enron Anulación, \$65.

73 MCI Anulación, §24-25. Ver también: ADC Affiliate Ltd y ADC \& ADMC Management Ltd c Hungría, Caso CIADI No. ARB/03/16, Laudo del 27 de septiembre de 2006 (en adelante: $A D C$ c. Hungría), $\$ 293$.

74 El presidente de todos estos casos lo explica en un articulo, Kaufmann-Kohler, "Arbitral Precedent: Dream, Necessity or Excuse?”, 23, (3) Arbitration International, 2007, 357 p. 374.

75 Véase en este sentido Sprecher, "The Development of the Doctrine of Stare Decisis and the Extent to Which It Should be Applied", p. 505; Commission, "Precedent", op. cit., p. 134; Zander, The Law Making Process, 6a. ed., 2004, p. 215, 302-3. 
en cuenta intereses que van más allá de los intereses de las partes en disputa. Pero esto es una facultad del tribunal arbitral, no un deber.

Asimismo, el árbitro no puede brindar seguridad jurídica. Seguridad jurídica implica la existencia de una seguridad jurídica objetiva (accesibilidad) y subjetiva (expectativas legítimas). ${ }^{76}$ La accesibilidad implica publicidad y claridad de la ley; en otros términos, que la ley sea calculable y confiable. ${ }^{77}$ Las expectativas legítimas se vinculan con la seguridad que una persona tiene acerca de la realización de sus propias expectativas y las consecuencias legales de su conducta. ${ }^{78}$ Ninguno de esos elementos parece existir en el arbitraje de inversiones. En primer lugar, no existe accesibilidad, ya que si bien existe cierta previsibilidad, la dispersión y multiplicidad de tribunales impide que la jurisprudencia arbitral pueda establecerse claramente. Para tal comprensión, hace falta sistematizarlos, hace falta una voluntad (arbitral o doctrinal) que los considere con tal normatividad. ${ }^{79}$ Por otra parte, la legitimidad de las expectativas individuales depende en gran medida de la existencia de seguridad objetiva y mientras haya menos seguridad objetiva, las expectativas estarán menos protegidas. ${ }^{80}$ Ello no significa que la jurisprudencia arbitral no contribuya a brindar una cierta previsibilidad y a ser demostración de un status quo. Pero la seguridad jurídica no es su objetivo ni su resultado natural.

\section{Cuatro razones por las cuales los tribunales arbitrales se citan}

La falta de obligatoriedad del precedente no significa que el precedente carezca de toda fuerza. El precedente aun cuando no es obligatorio es frecuentemente seguido por el árbitro y sirve de base para sus decisiones. Ello llevó a algunos autores a referirse al valor persuasivo del

76 Popelier, “Five Paradoxes on Legal Certainty and the Law Maker”, II, (1) Legisprudence 47 , p. 48.

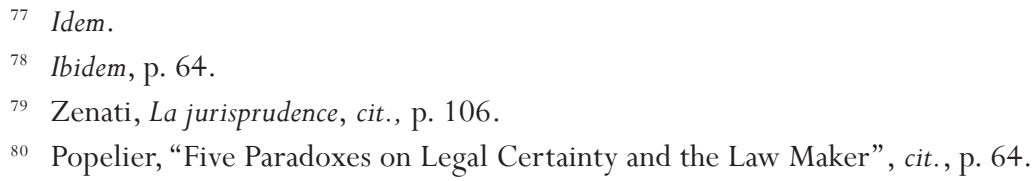


precedente ${ }^{81}$ el cual posee autoridad, sólo que ella no deriva de la amenaza a una sanción sino de otros factores que paso a analizar.

\section{A. Porque es útil}

En primer lugar, el precedente se cita por ser un buen ejemplo del ejercicio de la actividad de juzgar. Así, los tribunales se refieren a su valor ilustrativo, instructivo, ${ }^{82}$ útil, ${ }^{83}$ de servir de guía, ${ }^{84}$ o de iluminación ${ }^{85} \mathrm{O}$ por ser fuente de inspiración. ${ }^{86}$ La función jurisdiccional no es fácil. "Las decisiones judiciales no son argumentos sólidos basados deductivamente en hechos indiscutibles, sino interpretaciones defendibles de diferencias fácticas y legales". ${ }^{87}$ Es el resultado de una difícil tarea de contrabalancear posiciones jurídicas en un contexto social y económico determinado. Ello más aún en el arbitraje de inversiones dado que, como se mencionó previamente, el tribunal aplica varios órdenes jurídicos que tiene que coordinar. Así, cada decisión se convertirá en una experiencia valiosa para otros árbitros en casos similares, quienes si bien no están obligados a hacer uso del precedente, pueden y quieren hacerlo. ¿Por qué

${ }^{81}$ Kaufmann-Kohler, “Arbitral Precedent”, cit., p. 358; Bjorklund, "Investment Treaty Arbitral Decisions as Jurisprudence Constante”, en Picker et al. (eds.), International Economic Law: The State and Future of the Discipline, 2008, p. 270; Paulsson, "The Role of Precedent in Investment Arbitration”, en Yannaca-Small (ed), Arbitration Under International Investment Agreements A Guide to the Key Issues, 2010, 699, p. 710; Reinisch, 'The Role of Precedent in ICSID Arbitration', in Klausegger and Klein (eds.), Austrian Arbitration Yearbook, 2008, p. 499.

82 Liberian Eastern Timber Corp. (LETCO) c. Liberia, Caso CIADI No. ARB/83/1, Laudo del 31 de marzo de 1986, 89 ILR 1994, p. 232.

${ }^{83}$ Azurix Corp c.Argentina, Caso CIADI No.ARB /01 / 12, Laudo, 23 de junio de 200 (en adelante: Azurix Laudo), §391.

${ }^{84}$ Marvin Roy Feldman Krapa c. Estados Unidos Mexicanos, Caso CIADI No. ARB(AF)/99/1 ), laudo del 16 de diciembre de 2002 (en adelante: Marvin Roy c. México), §107.

85 Grand River Enterprises Six Nations, Ltd., et Al. c. Estados Unidos de America, Decisión sobre jurisdicción del 20 de julio de 2006, TLCAN/CNUDMI; RosInvest Co UK Ltd c. Rusia, Caso SCC No. V079/2005, Decisión sobre jurisdicción del 5 de octubre de 2007 (en adelante: RosInvest c. Rusia), §49.

86 AES c. Argentina Jurisdicción, $\$ 31$.

87 Cole, “Authority and Contemporary International Arbitration", 70 Louisiana Law Review, 2010, 802, p. 810. 
desaprovechar lo que ya existe? El precedente arbitral es conveniente, expedito y económico.

Evidentemente todas las decisiones arbitrales no están en un pie de igualdad y existen decisiones tanto buenas como malas. El precedente, o el precedente persuasivo, representa la buena, el resultado del ejercicio diligente de la actividad de juzgar. Por lo general, ello va a depender de su contenido, del proceso seguido para adoptarla y de la persona del árbitro.

En primer lugar, el precedente será persuasivo cuando represente una decisión coherente, convincente y justa a los ojos del árbitro. Ello depende no sólo de la técnica argumentativa y de la calidad formal del razonamiento, también de cuestiones extra-jurídicas, tales como políticas, económicas y sociales. Evidentemente, sólo aquellas interpretaciones que estén basadas en valores compartidos tendrán éxito y podrán ser persuasivas. ${ }^{88}$

En segundo lugar, la decisión, como toda decisión jurisdiccional, goza de autoridad procesal ya que es el resultado de un contradictorio. El proceso asegura que las pretensiones de ambas partes sean oídas y consideradas. Esas garantías procesales aseguran a las partes que sus pretensiones serán juzgadas con cuidado y prudencia, no solamente en cuanto al conocimiento de los hechos y la apreciación de las pruebas, sino también en cuanto a la búsqueda del principio correcto para alcanzar la solución justa. ${ }^{89}$ En este sentido, el precedente goza de la autoridad de haber sido adoptado en un proceso diligente. ${ }^{90}$

Finalmente, la persona del árbitro es clave y la misión del árbitro, así como la relación jurídica existente entre las partes y los árbitros, es intuitu pesonae. ${ }^{91}$ En general, los árbitros son elegidos en función de sus cualidades personales y su experiencia respecto a la controversia, ya sean estas de orden moral (la capacidad del árbitro para adoptar me-

88 Dicha noción fue muy bien elaborada por Fish, aunque no comparto la postura del autor que el intérprete está condicionado por dichos presupuestos. Fish, There's No Such Thing as Free Speech. And it's a Good Thing Too, 1994, p. 173.

89 Zenati, La jurisprudence, cit., p. 94.

90 Cole, “Authority", cit., p. 851.

91 Clay, L'arbitre, cit., p. 505. 
didas justas) o técnico (su experiencia y reputación ${ }^{92}$ ). Destáquese que entre los árbitros se encuentran ex jueces de la Corte Internacional de Justicia, ex miembros del órgano de apelaciones de la Organización Mundial del Comercio, el ex presidente del Consejo de Seguridad de las Naciones Unidas, rapporteurs de la Comisión de Derecho Internacional y presidentes de instituciones arbitrales. ${ }^{93}$ Una decisión de estos árbitros da al precedente una autoridad considerable.

\section{B. Para ser coherentes}

Como mencioné supra, algunos laudos evocan la idea de que el árbitro debe seguir lo establecido en una línea de casos a fin de velar por el desarrollo del derecho de las inversiones, en especial para velar por su coherencia y previsibilidad. Efectivamente, uno de los motivos que tienen los árbitros para citar precedentes es el de ser coherentes. Pero como se analizó allí también, ello no es porque el árbitro tenga el deber de hacerlo.

Pero los árbitros quieren ser coherentes. ¿Por qué? Para responder a esto es útil referirse a la teoría económica de la elección racional aplicada al derecho. ${ }^{94}$ Sin bien dicha teoría ha sido utilizada muy poco en el arbitraje internacional, ${ }^{95}$ ella ha sido empleada para analizar el comportamiento de los jueces y el impacto que el precedente tiene a la hora de decidir. ${ }^{96}$ Dada la similitud existente entre las funciones del juez y del árbitro, dicha teoría puede ser útil para comprender por qué los árbitros usan precedentes arbitrales. La teoría ha procurado entender la cita de precedentes en virtud de principios económicos; en especial,

92 Wälde, "The Specific Nature of Investment Arbitration”, op. cit, p. 51.

93 Paulsson, "International Arbitration and the Generation of Legal Norms: Treaty Arbitration and International Law", en v.d. Berg (ed.), International Arbitration 2006: Back to Basics, 2007, 879-889, p. 882.

94 Murphy, Courts, Judges, and Politics, 5a. ed., 2002; Posner, "Past-Dependency, Pragmatism, and Critique of History in Adjudication and Legal Scholarship", 67, (3) U Chi L Rev, 2000, 573; Landes and Posner, "Legal Precedent: A Theoretical and Empirical Analysis", 19 Journal of Law and Economics, 1976, p. 249; Gerhardt, "The Limited Path Dependency of Precedent", cit.

95 Cuniberti, "Beyond Contract-The Case for Default Arbitration in International Commercial Disputes”, 32 Fordham Int'l LJ, 2008.

96 Posner, How Judges Think, 2008. 
el de la maximización de utilidades. ${ }^{97}$ Así, el comportamiento de los árbitros puede asimilarse al de los agentes de mercado, tendiendo a maximizar su utilidad o beneficio y a reducir los costos o riesgos. ${ }^{98} \mathrm{El}$ árbitro como cualquier individuo prefiere más de lo bueno y menos de lo que les cause mal. Esta racionalidad tiene que ver con una cierta intuición que lleva a los individuos a optimizar y mejorar sus condiciones. Normalmente, los árbitros van a procurar obtener prestigio, promover el interés público, satisfacer los intereses de las partes o tener más reputación. En especial, dada la no permanencia de los tribunales arbitrales, el árbitro va a necesitar conseguir trabajo en el futuro. La coherencia y el mantenimiento de un status quo son elementos que van a permitir al árbitro maximizar estos beneficios. La razón es simple. La aplicación del derecho no es mecánica y la indeterminación del derecho permite al tribunal arbitral llegar a una serie de interpretaciones posibles. Al mismo tiempo, el derecho proclama ser racional y universal ${ }^{99}$ y, por tanto, las exigencias de motivación exigen al tribunal no sólo mostrar que su decisión es una de las tantas permisibles sino que ella es la correcta. ${ }^{100}$ Para ciertas corrientes esto puede ser denominado como un falso "cosmopolitan dream” ${ }^{101}$ o pura ilusión, ${ }^{102}$ pero lo cierto es que los sujetos esperan que el derecho sea racional y coherente.

Toda modificación o cambio en la manera de aplicar el derecho, implica una situación incomoda para el árbitro. En primer lugar, implica una modificación del status quo. En segundo lugar, puede ser menos persuasiva respecto de las partes (y futuros clientes) y de sus colegas

97 Thompson, "Applying Rational Choice Theory to International Law: The Promise and Pitfalls”, XXXI Journal of Legal Studies (2002) S285, p. 285.

98 Posner, "Past-Dependency", cit.; Vadi, “Towards Arbitral Path Coherence \& Judicial. Borrowing: Persuasive Precedent in Investment Arbitration”, 5, (3) Transnational Dispute Management, 2008.

99 Fish, There is No Such Thing as Free Speech, cit., p. 143.

100 Aguiló Regla, Teoría general de las fuentes del derecho, cit., p. 121. Fish, There is No Such Thing as Free Speech, cit., p. 143.

101 Kennedy, 'One, Two, Three Many Legal Orders: Legal Pluralism and the Cosmopolitan Dream’, 31 New York University Review of Law and Social Change, 2007, 641, p. 646.

102 Ello es el caso del movimiento llamado “Critical Legal Studies”. Kennedy, A Critique of Adjudication (fin de siècle), 1998; Kennedy, "Critical Theory, Structuralism and Contemporary Legal Scholarship”, New Eng L Rev, 1985-6, 209. 
(otros tribunales) que ya se han pronunciado de modo diferente. En tercer lugar, ello puede poner en peligro la legitimidad de los árbitros y el hecho de que en lugar de aplicar derecho estén haciendo política y siendo arbitrarios. Por tal motivo, restringir o eliminar un precedente tiene un gran $\operatorname{costo}^{103}$ y el árbitro tratará de minimizar toda tendencia a la divergencia, preservando la apariencia de continuidad y estabilidad. ${ }^{104}$ No obstante, ello no significa que los árbitros siempre sigan lo decidido previamente por otros tribunales. Ello va a depender de un consenso social que excede lo jurídico, por lo que en muchos casos ellos van a disentir. No obstante, tal necesidad de ser coherentes va a impulsar a los árbitros a explicar cuidadosamente por qué no siguen las decisiones previas, llegándose a exámenes súper exhaustivos, como se explicó respecto de $S G S$ c. Filipinas al rechazar lo decidido en $S G S$ c. Pakistán.

\section{Por qué las partes definen sus pretensiones mediante precedentes arbitrales}

Una razón muy frecuentemente citada por los tribunales arbitrales al justificar el uso del precedente arbitral es que las partes se hayan referido a ellos. ${ }^{105}$ Es práctica generalizada que las partes y sus abogados lo hagan. ${ }^{106}$ Así, el precedente se vuelve el lenguaje en el que las partes van a defender sus intereses en el proceso. Un aspecto muy importante del arbitraje es que él opera en un túnel creado e iluminado principalmente por los abogados de las partes. ${ }^{107}$ Ellas no sólo determinan el objeto de la controversia (litis) sino que construyen el marco conceptual y fáctico en virtud del cual el tribunal opera. ${ }^{108}$ En la práctica, el arbitraje tiende a ser dirigido por las partes, y moderado y monitoreado por el tribu-

103 Posner, How Judges Think, cit., p. 39.

104 Ibidem, p. 45.

105 El Paso Energy International Co. c. Argentina, Caso CIADI No. ARB/03/15, Decisión sobre jurisdicción del 27 de abril de 2006 (en adelante: El Paso c. Argentina Jurisdicción), §39.

106 BP America Production Co. y otros c. Argentina, Caso CIADI No ARB/04/8, Decisión sobre jurisdicción, 27 de julio de 2006 (en adelante: BP c. Argentina Jurisdicción), §42.

107 Wälde, “The Specific Nature of Investment Arbitration”, cit., p. 52.

108 Idem. 
nal. El precedente arbitral, en la medida que es usado por las partes, se convierte en el lenguaje del proceso y legitima su cita por el tribunal.

En Renta 4, el tribunal dijo que los árbitros "están obligados a hacerlo (considerar los precedentes) como parte de su deber básico de considerar los argumentos de las partes”. ${ }^{109}$ Aquí, parecería que el hecho que las partes se refieran a precedentes arbitrales toma una fuerza obligatoria, ya que se vincula con la obligación del árbitro del debido proceso. No obstante, si se considera el principio iura novit curia como aplicable al arbitraje, ${ }^{110}$ el árbitro es libre de seguir o no el contenido que las partes pretendan dar al derecho con los precedentes arbitrales. Es difícil determinar si una omisión del tribunal arbitral en tal sentido puede constituir una causal de anulación en el Convenio del CIADI (extralimitación manifiesta de facultades, violación grave de una regla de procedimiento o falta de motivación). Mientras que algunos autores se han pronunciado favorablemente acerca de dicha posibilidad, ${ }^{111}$ lo cierto es que ello dependerá del rol que se les reconozca a los comités de anulación del CIADI. Mientras que desde una perspectiva restrictiva, el comité ad hoc carece de poder para revisar la aplicación concreta del derecho al caso; una visión extensiva, como aquella existente en las decisiones de los comités de anulación en los casos Sempra y Enron, permite concebir aquellas interpretaciones que desnaturalicen la regla como una extralimitación manifiesta de las facultades del árbitro. ${ }^{112}$

\section{Por qué el modo de decidir representa un consenso}

Dado que los árbitros son libres de seguir precedentes o no, la cita de un precedente constituye una aceptación del criterio decisorio, un visto bueno. Ello permite construir consensos respecto al modo de decidir

109 Renta 4 SVSA and ors c. Rusia, Caso SCC No. 24/2007, Decisión sobre jurisdicción, 20 de marzo de 2009 (en adelante: Renta 4 c. Rusia Jurisdicción), §16.

110 Giovannini, "International Arbitration and Jura Novit Curia - Towards Harmonization”, in Fernández et al. (eds.), Liber Amicorum Bernardo Cremades (2010) 495, pp. 495 y ss.

111 Commission, "Precedent", cit., p. 156; Schreuer, "Diversity and Harmonization of Treaty Interpretation in Investment Arbitration", 3, (2) Transnational Dispute Managment, 2006, p. 15.

112 Sempra Anulación, §162-163. 
una categoría de controversias jurídicas. Siguiendo a Chaïm Perelman, podemos decir que el árbitro, en su relación con sus pares, se dirige como si se tratase de una audiencia, un auditorio universal. ${ }^{113}$ Ello lleva a evaluar sus opiniones, las que van a ser examinadas por dicho auditorio desde el punto de vista de los otros, a fin de adquirir el valor persuasivo que el árbitro desea. El auditorio universal (también referido como comunidad interpretativa) $)^{114}$ permite evaluar un sentimiento respecto a lo que pueden decir los otros al respecto. ${ }^{115}$ Por tal motivo, el auditorio constituye una limitación para la decisión, la que sólo va adquirir autoridad persuasiva si es aceptada por dicho auditorio. El auditorio en el arbitraje de inversiones está constituido por los tribunales arbitrales principalmente. Empero, forman parte de dicho auditorio una red social más amplia, como los tribunales nacionales y los comités ad hoc del CIADI, y la doctrina.

En primer lugar, la autoridad del precedente va a depender de la aceptación de otros tribunales arbitrales. ${ }^{116}$ Mientras que la cita de precedentes se erige como un mecanismo para obtener consenso respecto del modo de decidir ciertas cuestiones, una vez adquirido ese carácter consensual, la solución tendrá por efecto el marginalizar las interpretaciones alternativas. ${ }^{117}$ Por el mismo motivo, cuando el precedente se critique o se reduzca su aplicabilidad en virtud de distinciones que excluyan de su aplicación casos similares, su carácter consensual se debilitará y, dado que los tribunales son muy exhaustivos al tratar aquellos precedentes que no comparten y respecto de los cuales existen divergencias, los puntos flojos de la argumentación jurídica se pondrán al descubierto afectando su autoridad.

113 Perelman, La nouvelle rhétorique. Traité de l'argumentation, Editions de l'Université de Bruxelles, 1992.

114 Fish, There is No Such Thing as Free Speech, cit., p. 167-73; Bianchi, "Looking ahead: international law's main challenges", en D. Armstrong (ed.), Routledge Handbook of International Law, 2009, 392-409, p. 404-405.

115 Allard, "Le dialogue des juges dans la mondialisation”, Le dialogue des juges. Actes du colloque organisé le 28 avril 2006 à l’Université de Bruxelles, 2007, 77, p. 86-87.

116 Jacquet, 'Avons-nous besoin de jurisprudence arbitrale?' (3) Revue de l'arbitrage, 2010, 445.

117 Bianchi, “Looking ahead: international law's main challenges”, cit., p. 404. 
En segundo lugar, el valor del precedente va a depender de las decisiones de los comités ad hoc del CIADI así como los de tribunales nacionales en los procesos de anulación y ejecución de sentencias arbitrales. Si bien estos tribunales no pueden revisar si la aplicación del derecho es correcta (los errores de derecho), en algunos casos, los comités de anulación del CIADI, han ido mas allá de este rol, ya sea anulando la decisión por errores de derecho, ${ }^{118}$ o declarando la existencia de tal error en obiter dicta, a pesar de que dicho error no califica como causal de anulación. ${ }^{119}$ Dichas declaraciones, si bien no borran el efecto de cosa juzgada de la decisión, afectan la autoridad del precedente, el que deja de representar una decisión correcta.

La doctrina, aunque desde un punto de vista distinto, se pronuncia sobre la calidad de los laudos, critica los malos y cumple una tarea de sistematización, haciéndolos fáciles de utilizar. La tarea de sistematización se vuelve fundamental tanto para el abogado que la va a usar para argumentar su caso, como para el tribunal a fin de conocer una cuestión más detalladamente. Mientras más laudos haya, más necesaria se volverá la doctrina.

4. Circunstancias en las que los tribunales arbitrales se citan

De la práctica arbitral pueden extraerse ciertas condiciones de cita de precedentes arbitrales. A modo general puede decirse que los límites de toda cita de precedentes están dados por los poderes y obligaciones del árbitro. Lo cierto es que es difícil que la cita de precedentes pueda violar alguna de estas obligaciones, pues ello forma parte de su poder de resolver la controversia jurídica con base en derecho. Asimismo, la cita de precedentes va difícilmente a calificar como causal de anulación o de rechazo de ejecución del laudo, a no ser que el error sea tan flagrante que pueda constituir una no aplicación del derecho in totum. ${ }^{120}$

118 Tales como en Klöckner I Anulación; Amco Asia Anulación §22; Enron Anulación; Sempra Anulación.

119 CMS Anulación, $\$ 121$ (respecto al estado de necesidad).

120 Según la postura flexible seguida por el comité de anulación en Sempra que mencioné previamente. Sempra Anulación, §62-63. 


\section{A. Hipótesis similares}

En primer lugar, dado que la cita de precedentes se basa en un método analógico, la buena aplicación del precedente es aquella que relaciona análogos. ${ }^{121}$ El modo tradicional para determinar la relevancia de precedentes y su aplicabilidad es aquel que analiza las similitudes y diferencias en términos de contexto, alcance y efecto de las normas, remedios, proceso, objetivos y actores en cuestión. ${ }^{122}$ Ello no significa que los hechos y el derecho deban ser idénticos o muy similares. Puede suceder que los hechos no sean similares, pero sí la cláusula a interpretar. En tal caso, los tribunales arbitrales generalmente hacen uso del precedente. No obstante, los tribunales deben ser cautos a la hora de comparar las disposiciones, ya que como mencionó el tribunal en AES c. Argentina:

25. Este es especialmente el caso si se considera que similitudes sorprendentes en la redacción de los TBI muchas veces ocultan diferencias reales en la definición de algunos conceptos clave, como puede ser el caso de la definición de "inversiones" o de los derechos y obligaciones de cada parte.

Asimismo, los tribunales citan precedentes cuando los hechos son similares pero no los TBI. Tal es el caso del gran numero de casos contra Argentina en virtud de la crisis económica de 2001, respecto de los cuales, los tribunales arbitrales adoptaron la misma definición del estándar del trato justo y equitativo aun cuando las cláusulas de trato justo y equitativo de cada TBI eran distintas entre sí, pero se trataba de los mismos hechos. La razón es que al tratarse de un estándar, su aplicación exige que los tribunales valoren la situación concreta del caso litigioso para determinar sus consecuencias. ${ }^{123}$ En otras palabras, dichos prototipos de conducta requieren del árbitro una decisión personal acerca

121 Gibson and Drahozal, "Iran-United States Claims Tribunal Precedent in Investor-State Arbitration”, 23, (6) Journal of International Arbitration, 2006, 521, p. 531.

122 Wälde, “The Specific Nature of Investment Arbitration”, cit., p. 110.

123 Stone, “Interpretations of Modern Legal Philosophies”, cit., p. 708. 
de lo que la justicia exige en vista de las circunstancias concretas que el caso ofrece. ${ }^{124}$

B. ¿Debe el precedente ser constante?

La doctrina y jurisprudencia a veces exigen que el precedente corresponda a una jurisprudencia constante. ${ }^{125}$ Ello es el caso, por ejemplo, en Bureau Veritas, donde el tribunal arbitral justificó no seguir los precedentes arbitrales citados por las partes ya que "no hay jurisprudencia constante sobre el efecto de las cláusulas paraguas, [y] el tema es uno en los que la opinión jurídica está muy dividida”. ${ }^{126}$ No obstante, estas cuestiones son factores o elementos que hacen a la autoridad del precedente, pero su ausencia no impide la cita. Como mencioné supra el árbitro es libre de citar o seguir precedentes arbitrales, es una facultad. Por tal motivo, él puede seguir precedentes que no son constantes o respecto de los cuales existen muy pocos. La coherencia o constancia de un precedente, le da autoridad, pero no impide que otros precedentes se sigan. Ello explica el hecho de que en cuestiones controvertidas sobre las que no existe consenso, los tribunales arbitrales se adhieran a una u otra corriente.

\section{C. ¿Precedentes definitivos?}

Como se explicó supra, los laudos arbitrales son definitivos, pero están sujetos a procesos de anulación. Cabe preguntarse si los tribunales citan precedentes arbitrales contra los cuales puede proceder un recurso de anulación o aún más cuando éstos fueron anulados. En la práctica los tribunales arbitrales citan precedentes contra los cuales puede proceder un recurso de anulación o que han sido anulados. Ello es, por ejemplo,

124 Respecto de los jueces véase ibidem, p. 235.

125 Di Pietro, “The Use of Precedents in ICSID Arbitration: Regularity or Certainty?" (3) International Arbitration Law Review (2007) 92, p. 96. Bureau Veritas, Inspection, Valuation, Assessment and Control, BIVAC BV c. Paraguay, Caso CIADI No. ARB/07/9, Decisión sobre jurisdicción, 29 de mayo de 2009 (en adelante: Bureau Veritas c. Paraguay), §141; Wena Hotels Anulación, §49.

126 Bureau Veritas v. Paraguay, §141; Helnan International Hotels AS c. Egipto, Decisión del comité de anulación, Caso CIADI No. ARB/05/19 (en adelante: Helnan Anulación), §49. 
el caso de CMS c.Argentina respecto de la cláusula paraguas, el que fue citado en Joy Mining y LG\&E estando el proceso de anulación pendiente. ${ }^{127}$

Esta práctica es coherente con el hecho de que la anulación no es un verdadero recurso de apelación y no afecta el valor del razonamiento del tribunal ni de las soluciones adoptadas. Pero, como se mencionó supra, las decisiones de los comités de anulación pueden afectar la autoridad del precedente, en la medida que dichos procesos permitan al comité pronunciarse sobre el modo de aplicar el derecho. Empero, todos tienen el mismo test de calidad. Así, una decisión de un comité de anulación tendrá valor persuasivo en función de su calidad. De hecho, existen decisiones de comités de anulación que han tenido un impacto considerable. Piénsese en la decisión del comité de anulación en Vivendi $I$, respecto de la distinción entre contract claims-treaty claims, la que ha sido muy seguida y citada. ${ }^{128}$

\section{Ratio decidendi y obiter dicta}

En Renta 4 el tribunal arbitral sostuvo que el uso del precedente debería limitarse, como en la doctrina stare decisis, a la ratio decidendi. ${ }^{129}$ Según este sistema sólo la ratio decidendi, esto es, el principio o los principios necesarios para decidir el caso, forman parte del precedente obligatorio, y no el obiter dictum. ${ }^{130}$ Dado que en el arbitraje de inversiones no existe un sistema de stare decisis, dicha postura implicaría que los árbitros sólo pueden citar y seguir lo contenido en la ratio decidendi de decisiones previas. No obstante, el comité ad hoc en Amco Asia, declaró que dado que no está obligado a seguir precedentes, no resulta necesario distinguir entre la ratio decidendi y el obiter dictum. ${ }^{131}$ Ello tiene funda-

127 Joy Mining Machinery Limited c. Egipto, Caso CIADI No. ARB/03/11, Decisión sobre jurisdicción, 6 de agosto de 2004 (en adelante: Joy Mining Jurisdicción), at § 64-82; LG\&E Laudo, $\S 164-165$.

128 Joy Mining Jurisdicción, §75; Bayindir c. Pakistán Jurisdicción, §166; Consortium RFCC c. Maruecos, Caso CIADI No. ARB/00/6, Laudo, 22 de diciembre de 2003, §41; Impregilo SpA c. Pakistán, Caso CIADI No. ARB/03/3; Decisión sobre jurisdicción, 22 de abril de 2005, \$256.

129 Renta 4 c. Rusia Jurisdicción, $\$ 91$.

130 Sprecher, "The Development of the Doctrine of Stare Decisis and the Extent to Which It Should be Applied”, p. 503.

131 Amco Asia Anulación, §44. 
mento en que si bien en los sistemas de common law, sólo la ratio decidendi puede constituir un precedente obligatorio, los obiter dicta constituyen precedentes persuasivos. Dado que en el arbitraje de inversiones el precedente no es obligatorio sino persuasivo, la distinción es irrelevante.

En la práctica, existen tribunales arbitrales que no hacen la distinción y citan obiter dicta. Ello es el caso de la decisión del comité ad hoc en Enron, la que cita los obiter dicta de MTD, en cuanto al valor del precedente arbitral, y del comité ad hoc de Azurix, en el que el comité sigue el razonamiento del comité en Azurix sobre los reclamos indirectos de los accionistas en detalle. ${ }^{132}$

\section{EL RESULTADO DEL USO DEL PRECEDENTE ARBITRAL EN EL ARBITRAJE DE INVERSIONES}

Como se mencionó al definir la jurisprudencia, está constituida por soluciones generales extraídas de una serie repetida y coherente de decisiones. Ya hemos visto que los tribunales arbitrales, a pesar de ser autónomos e independientes entre sí, tienen acceso a decisiones motivadas de otros y tienden a citarse, ya sea para motivar una decisión determinada o para divergir con lo decidido previamente. La pregunta que corresponde responder ahora es cuál es el resultado de tal práctica, en otras palabras, ¿existen soluciones generales arbitrales? Como se verá en las siguientes páginas, existen coherencias pero también divergencias importantes.

\section{Las coherencias}

En el derecho de las inversiones pueden encontrarse varios ejemplos de soluciones coherentes. El primer ejemplo es el de la admisión de las demandas arbitrales fundadas en una oferta unilateral contenida en

132 Véase por ejemplo la decisión del comité ad hoc en Enron sobre MTD en cuanto al valor del precedente arbitral (§ 63-67) y sobre los reclamos indirectos de los accionistas en la que el comité se basa en el razonamiento del comité ad hoc en Azurix; Enron Anulación, §113-123. 
un tratado. Ni el Convenio del CIADI ni los travaux préparatoires habían previsto la posibilidad de que el consentimiento al arbitraje pueda darse mediante un tratado. ${ }^{133}$ El Informe de los directores ejecutivos del Banco Mundial, por su parte, sólo menciona como posibles ejemplos el acuerdo arbitral (cláusula arbitral o compromiso) o una disposición contenida en una ley nacional. Desde el primer caso fundado en un TBI, AAPL c. Sri-Lanka, se han admitido dichas demandas en forma sistemática a pesar del silencio del convenio del CIADI y el debate doctrinal acerca de lo que J. Paulsson denominó arbitration without privity. ${ }^{134}$ Como mencionó Brigitte Stern, el principio se ha establecido de tal forma que los tribunales ni siquiera tienen la necesidad de discutirlo. ${ }^{135}$

El segundo ejemplo de soluciones coherentes es el de la admisibilidad de la demanda del accionista extranjero de una sociedad constituida en el Estado receptor para reclamar por la indemnización de daños y perjuicios indirectos sufridos en virtud de la violación de contratos y concesiones concluidos con sus filiales. El derecho de accionistas extranjeros para reclamar por daños indirectos fue analizado por la CIJ en el caso Barcelona Traction. Allí la CIJ declaró que en derecho internacional general, el Estado no tiene legitimación para reclamar la protección diplomática de los accionistas por los daños a la sociedad en que estos tienen sus acciones. ${ }^{136}$ En la gran mayoría de los procesos iniciados por accionistas de sociedades locales, la mayoría contra Argentina, la demandada objetó que no existe en derecho internacional un derecho del accionista a reclamar por los derechos de la sociedad local, y que el alcance de estos se limita a los derechos de los accionistas según su estatuto de socio en virtud de la lex societatis (voto, dividendos, cuota de liquidación, etcétera). Los tribunales rechazaron sistemáticamente dicha excepción dado que el accionista reclama por sus derechos derivados del tratado y no por los derechos de la sociedad local. El término acciones contenido en las definiciones de inversión de los TBI's, para todos estos tribunales, se define en su sentido ordinario según el artículo 31(1) de la Convención

133 Stern, "Le consentement à l'arbitrage CIRDI”, cit., pp. 223 y ss.

134 Paulsson, "Arbitration without privity", 10, (2) ICSID Review, 1995.

135 Gaillard and Banifatemi, Precedent in international arbitration, 2008, p. 149.

136 Caso relativo a la Barcelona Traction, Light and Power Company (Bélgica c. España) [1970] CIJ Rep 44, §33. 


\section{de Viena sobre el Derecho de los Tratados y no en virtud del derecho de}

la sociedad o del silencio del derecho internacional general. ${ }^{137}$ Las decisiones en este sentido no sólo son unánimes, sino que representan más de $25 .{ }^{138}$

137 Douglas, The International Law of Investment Claims, 2009, p. 407.

138 Antoine Goetz y otros c. Republica de Burundi, Caso CIADI núm. ARB/95/3, Laudo del 10 de febrero de 1999, 15 ICSID Rev._FILJ 457 (2000) (en adelante: Goetz c. Burundi), §89; Emilio Agustín Maffezini c. el Reino de España, Caso CIADI núm. ARB/97/7, Decisión sobre jurisdicción del 25 de enero de 2000, 5 ICSID Rep. 396 (2002) (en adelante: Maffezini Jurisdicción), \$88/70; Compañia de Aguas del Aconquija SA andVivendi Universal SA c. Argentina, Decisión sobre jurisdicción, Caso CIADI núm. ARB/97/3, 14 de noviembre de 2005; Azurix Corp.c.. República Argentina, Caso CIADI núm. ARB/01/12, Decisión sobre jurisdicción del 8 de diciembre de 2003, §72-76; LG\&E Energy Corp., LG\&E Capital Corp. and LG\&E International Inc. c. República Argentina, Caso CIADI núm. ARB/02/1, Decisión sobre jurisdicción del 30 de abril de 2004, $\S 50$ y LG\&E Laudo, §177; American Manufacturing \& Trading, Inc c. Estados Unidos de América, Laudo y opinión individual, Caso CIADI núm. ARB/93/1, 11 de febrero de 1997, §5.14; Alex Genin and others c. Republic of Estonia, Caso CIADI núm. ARB/99/2, Laudo del 25 de junio de 2001; CME Czech Republic BV c. República Checa, Laudo parcial y opinión individual, Ad hoc-CNUDMI, 13 de septiembre de 2001, §375-377; Camuzzi International S.A. c. República Argentina, Caso CIADI núm. ARB/03/2, Decisión sobre jurisdicción del 11 de mayo de 2005, §7; Sempra Jurisdicción, §41; Gas Natural SDG. S.A. c. República Argentina, Caso CIADI núm. ARB/03/10, Decisión del 17 de junio de 2005 (en adelante Gas Natural), §35; AES c. Argentina Jurisdicción, §86-88; Continental Casualty Company c. República Argentina, Caso CIADI No. ARB/03/9, Decisión de jurisdicción, 22 de febrero de 2006, §78; Pan American Energy LLC y BP Argentina Exploration Company c. República Argentina, Caso CIADI núm. ARB/03/13, Decisión sobre excepciones preliminares del 27 de julio de 2006 (en adelante Pan American Jurisdicción) §213; Siemens A.G. c. República Argentina, Caso CIADI núm. ARB/02/8, Decisión sobre jurisdicción del 3 de agosto de 2004; §137-142; Total S.A. c. República Argentina, Caso CIADI núm. ARB/04/1, Decisión sobre jurisdicción del 29 de agosto de 2006, §78-81; CMS Gas Transmission Company c. República Argentina, Caso CIADI núm. ARB/ 01 / 8, Decisión sobre jurisdicción, 17 de julio de 2003, §40-65; CMS Anulación, §69; Lauder c. Republica Checa, Laudo, Ad hocCNUDMI; 03 de septiembre de 2001, §77; Lanco International, Inc. c. República Argentina, Caso CIADI núm. ARB/97/6, Decisión sobre jurisdicción, 8 de diciembre de 1998, §10; Champion Trading Company and Ameritrade International, Inc. c. República Árabe de Egipto, Caso CIADI núm. ARB/02/9, Decisión sobre jurisdicción del 21 de octubre de 2003, §18; Asian Agricultural Products Limited c. República Democrática socialista de Sri Lanka, Caso CIADI núm. ARB/87/3, Laudo y opinión disidente del 27 de junio de 1990, p. 95; Enron Creditors Recovery Corporation y Ponderosa Assets, L.P. c. República Argentina, Caso CIADI núm. ARB/01/3, Decisión sobre jurisdicción, 14 de enero de 2004, §49; SAUR International c. República Argentina, Caso CIADI núm. ARB/04/4, Decisión sobre jurisdicción, 27 de febrero de 2006, §87; Metalpar S.A. and Buen Aire S.A.c. República Argentina, Caso CIADI núm. ARB/03/5, Decisión sobre jurisdicción, 27 de abril de 2006, §68; Aguas Cordobesas S.A., Suez, y Sociedad General de Aguas de Barcelona 
Un tercer ejemplo de decisiones coherentes es aquel respecto de la interpretación del artículo 42 del Convenio del CIADI. Como se explicó supra, dicho artículo establece como derecho aplicable al fondo, en caso de ausencia de elección por las partes, de "la legislación del Estado que sea parte en la diferencia, incluyendo sus normas de derecho internacional privado, y aquellas normas de derecho internacional que pudieren ser aplicables". La disposición habiendo sido ideada para contratos, fue originariamente interpretada de modo a que el derecho internacional cumpla una relación subsidiaria (colmar lagunas) y jerárquica (de control). Pero dicha posición resultó insostenible luego de la aparición del arbitraje basado en tratados en los años noventa. Desde entonces, el derecho aplicable se internacionalizó y, salvo en determinados casos de renvoi o aplicación del derecho nacional para ciertas cuestiones, como por ejemplo la conformidad de la inversión con el derecho del Estado receptor, el derecho aplicable a los reclamos basados en un tratado es el derecho internacional. Consecuentemente, en un gran numero de laudos y decisiones de comités de anulación el derecho internacional apareció como primero en escena, dejando de tener carácter subsidiario. ${ }^{139}$ En virtud de la nueva interpretación de dicho artículo, cada orden jurídico no se encuentra en una relación de subordinación sino que rige materias distintas. No obstante, continúan las ambigüedades respecto de la relación entre ambos órdenes en cuestiones relativas a la cláusula paraguas y en materia de reclamos basados en contratos y leyes de inversiones.

S.A. c. República Argentina, Caso CIADI núm. ARB/03/17, Decisión sobre jurisdicción, 16 de mayo de 2006, §49; Para un análisis detallado de esta jurisprudencia véase Bentolila, “Shareholders' Action to Claim for Indirect Damages”, 2, (1) Trade, Law \& Development, 2010, 87.

139 Wena Hotels Anulación, p. 911; CMS Anulación, §115; LG\&E Laudo ; Azurix c. Argentina Laudo, §66; Goetz c. Burundi, §69; Tokios Tokelès c. Ucrania, Caso CIADI núm. ARB/02/18; Decisión del 29 de junio de 2007, §140; Duke Energy Electroquil Partners and Electroquil SA c. Ecuador, Caso CIADI núm. ARB/04/19, Laudo, 12 de agosto de 2008 (en adelante Duke c. Ecuador Laudo), $\S 118$; Autopista Concesionada deVenezuela CA (Aucoven) c.Venezuela, Caso CIADI núm. ARB/00/5, Laudo del 23 de septiembre de 2003, §102. 


\section{Las divergencias}

Asimismo, también existen grandes divergencias. Tales divergencias prevalecen entre otros, en materia de la cláusula de la nación más favorecida, la cláusula paraguas, y respecto a la definición de inversión en virtud de lo establecido por el artículo 25 del Convenio del CIADI. En primer lugar, respecto a si la cláusula de la nación más favorecida se aplica a derechos procesales, existen tres posturas. Para la primera, los derechos procesales, en especial las disposiciones arbitrales, constituyen un derecho esencial del inversor y deben ser protegidas por dicha cláusula; ${ }^{140}$ para la segunda, la aplicación de la cláusula se limita a cuestiones de admisibilidad, ${ }^{141}$ y para la tercera, la cláusula cubre derechos procesales cuando ello esté expresamente establecido en el tratado. ${ }^{142}$

Otro ejemplo categórico de dichas divergencias es el de la cláusula paraguas. Para una primera corriente (posición ascensor), la cláusula paraguas transforma cualquier relación contractual entre el inversor y el Estado a una obligación del tratado. ${ }^{143}$ Para una segunda corriente (posición restrictiva), la cláusula sólo eleva las violaciones del contrato a violaciones del tratado cuando existan circunstancias “excepcionales", tales como denegación de justicia. ${ }^{144}$ Para una tercer corriente (posición iure

140 Maffezini Jurisdicción §38-64, Gas Natural, §29; National Grid c. Argentina, Decisión del 29 de junio de 2006 (En adelante: National Grid); Suez-AWG, §46; Siemens Jurisdicción, §103; MTD equity Sdn Bhd. and MTD Chile SA c. Chile, Caso CIADI núm. ARB/01/7, Laudo, 25 de mayo de 2004; Suez-InterAgua c. Argentina, Decisión sobre jurisdicción, 16 de mayo de 2006, §60-66; RosInvest c. Rusia, §134-139.

141 National Grid, $\$ 91$.

142 Plama Consortium Limited c. Bulgaria, Caso CIADI núm. ARB/03/24, Decisión sobre jurisdicción, 8 de febrero 2005, §184-227; Salini Costruttori S.p.A. and Italstrade S.p.A. c. Jordan, Caso CIADI núm. ARB/02/13, Decisión sobre jurisdicción, 29 de noviembre de 2004, §115; Telenor c. Hungría, Caso CIADI núm. ARB/04/15, Laudo, 13 de septiembre de 2006; Wintershall Aktiengesellschaft c. Argentina, Caso CIADI núm. ARB/04/14, Laudo del 8 de noviembre de 2008, §160-197.

143 Noble Ventures Inc c. Rumania, Caso CIADI núm. ARB/01/11, Laudo, 12 de octubre de 2005, §54-62; Fedax c.Venezuela, Laudo del 9 de marzo de 1998, at § 29; LG\&E Laudo, §175; CMS Laudo, §86. LESI DIPENTA c. Alegría, (Consorzio Groupment LESI-DIPENTA c. Alegría, Laudo del 10 de enero de 2005, ICSID Rev. 19 - FILJ 426 (2004).

144 Société Générale du Surveillance SA c. Pakistan, Caso CIADI núm. ARB/01/13, Decision sobre jurisdiction, 6 de agosto de 2003, §168-161. 
imperii), la cláusula sólo protege una categoría limitada de contratos en los que el Estado aparece actuando con prerrogativas públicas, de iure imperii. ${ }^{145}$ Finalmente para la última corriente (posición enforcement), la cláusula paraguas protege cualquier contrato firmado con el Estado pero sin que ello modifique el alcance y la existencia del contrato, el cual continúa estando regido por el derecho del contrato. ${ }^{146}$ Gabrielle Kaufmannn-Kohler destaca que si bien estos tribunales han justificado la desviación jurisprudencial en la especificidad de la disposición convencional, la justificación no es suficiente para explicar todas las divergencias. ${ }^{147}$

Finalmente, es posible encontrar divergencias en el tratamiento de la definición de inversión a los fines del artículo 25 del Convenio del CIADI. Dicho artículo dispone que el tribunal arbitral tiene competencia respecto de aquellas diferencias jurídicas relacionadas directamente con la inversión, pero no define qué se entiende por inversión. Los travaux préparatoires evidencian que no existía consenso acerca de una definición y varios delegados manifestaron su descontento respecto a ciertos elementos tales como la duración de la inversión, ${ }^{148}$ la contribución, ${ }^{149}$ la magnitud, ${ }^{150}$ la inclusión de acciones ${ }^{151}$ y de contratos de construcción, ${ }^{152}$ entre otros. Desde los casos Fedax y Salini, se procuró definir el término “inversión” del artículo 25 del Convenio del CIADI según un célebre test que procura determinar si existe inversión en función de ciertos elementos: a) contribución; b) duración; c) participación en el riesgo, y d) contribución al desarrollo del Estado receptor. ${ }^{153}$ Dicho test ha sido

145 El Paso Jurisdicción, Pan American Jurisdicción, §99.

146 SGS c. Filipinas, §115-127; CMS Anulación, §100.

147 Kaufmann-Kohler, “Arbitral Precedent: Dream, Necessity or Excuse?”, cit.

148 History of the ICSID Convention. Documents concerning the origin and the formulation of the Convention on the Settlement of Investment Disputes between States and Nationals of other States, vol. II (1968), p. 625,668, 700, 703, 707.

149 Ibidem, pp. 702, 703, 708-710.

150 Ibidem, p. 34.

151 Ibidem, p. 661

152 Ibidem, p. 500.

153 Fedax NV c.Venezuela, Decisión sobre jurisdicción, 5 ICSID Rep. p. 183; Salini Costruttori S.p.A.y Italstrade S.p.A.c. Reino de Marruecos (Caso CIADI núm. ARB/00 /4) Decisión sobre jurisdicción del 23 de julio de 2001, 129 JDI 196 2002, §53. 
enormemente citado por otros tribunales; sin embargo, las decisiones no son unánimes ya que mientras que algunos tribunales, si bien siguiendo el test, rechazan el requisito de que deba contribuir al desarrollo del Estado; ${ }^{154}$ otros agregan elementos que originariamente el test no incluía como la buena fe $\mathrm{e}^{155} \mathrm{o}$ la conformidad de la inversión con el derecho del Estado receptor. ${ }^{156}$ Finalmente existen tribunales arbitrales que directamente rechazan el test en su totalidad considerando que el Convenio es flexible y no contiene ninguna definición. ${ }^{157}$

Tales divergencias han generado un gran debate entre académicos, profesionales e instituciones arbitrales acerca de la necesidad de crear mecanismos de apelación o simplemente modificar el sistema. ${ }^{158}$ Algunos autores hasta han llegado a decir que el sistema se halla inmerso en una crisis de legitimidad aunque no queda claro si se reclama por más integridad o por más coherencia. ${ }^{159}$ ¿Cómo es posible hablar de una jurisprudencia arbitral ante estas divergencias? Las divergencias significan la ausencia de soluciones generales. Los criterios jurisprudenciales al ser antagónicos se excluyen mutuamente y la divergencia representa una ausencia de consenso. Cabe preguntarse si la existencia de divergencias impide la existencia de una jurisprudencia arbitral. Evidente-

154 LESI, S.p.A. and Astaldi, S.p.A. c. Algeria, Caso CIADI núm. ARB/05/3, Decisión sobre jurisdicción, 12 de julio de 2006; Malaysian Historical Salvors, SDN, and BHD c. Malasia, Caso CIADI núm. ARB/05/10, Laudo, 17 de mayo de 2007, §123.

155 Phoenix Action Ltd. c. República Checa, Caso CIADI núm. ARB/06/5) Laudo del 15 de abril de 2009, 2009, §114-142.

156 Ibidem, p. 114

157 Biwater Gauff (Tanzania) Ltd c. Tanzania, Caso CIADI núm. ARB/05/22, Decision del 24 Julio de 2008, §312.

158 Acerca de dicho debate véase Charles N. Brower, A Crisis of Legitimacy, Nat'l L.J., Oct. 7, 2002; Judge Howard M. Holtzmann, A Task for the 21st Century: Creating a New International Court for Resolving Disputes on the Enforceability of Arbitral Awards, in The Internationalisation of International Arbitration: The LCIA Centenary Conference 109 (Martin Hunter et al. eds., 1995; Judge Stephen M. Schwebel, The Creation and Operation of an International Court of Arbitral Awards, in The Internationalisation of International Arbitration, p. 393; Franck, 'The Legitimacy Crisis in Investment Treaty Arbitration: Privatizing Public International Law Through Inconsistent Decisions', 73 Fordham Law Review, 2005, p. 87; Schreuer and Weiniger, “A Doctrine of Precedent?", in Muchlinski et al. (eds.), The Oxford Handbook of International Investment Law (2008), p. 1201.

159 Franck, 'The Legitimacy Crisis', op. cit. 
mente, ello dependerá de lo que se esperé de ella pero no debe olvidarse que existen divergencias aún respecto de tribunales domésticos y ella sigue siendo una jurisprudencia. En efecto, las divergencias no anulan las coherencias y hasta llegan a cumplir un rol importante en el proceso de creación de la jurisprudencia. ${ }^{160}$ No debe olvidarse tampoco que el arbitraje de inversiones se halla inmerso en un sistema autónomo y atomizado, donde los mandatos de cada tribunal varían en función de las múltiples bases de competencia, incluyendo una peculiar red de tratados bilaterales. Dada la diversidad de bases de competencia y de las fuentes de las obligaciones, y el hecho de que el uso del precedente arbitral dependa de la discreción del arbitro, el alcance de la jurisprudencia, de existir, va a ser mucho más limitado que en cualquier otro sistema. Como se demostró supra existen soluciones arbitrales coherentes. ¿Debemos ignorarlas por el simple hecho de que existen divergencias fundamentales? Dichas soluciones, no sólo forman parte del proceso arbitral y de la motivación de las decisiones con base en derecho, como se demostró en estas páginas, sino que son utilizadas por abogados y académicos para dar contenido a normas jurídicas abstractas y definir el arbitraje de inversiones. ${ }^{161}$ Ello es una razón más que suficiente para estudiarlas y procurar definir su estatus.

\section{CONCLUSIÓN}

Aunque el arbitraje es privado y autónomo y no está incluido en una estructura institucionalizada, las condiciones permitiendo la creación de soluciones generales arbitrales están presentes. Éstas son el hecho de que los laudos arbitrales son decisiones basadas en derecho, accesibles y motivadas, emitidas por tribunales similares en controversias similares.

160 Ancel et al., Les divergences de jurisprudence, 2003.

${ }^{161}$ De hecho, cualquier libro de arbitraje de inversiones o de derecho de inversiones se basa significativamente en la "jurisprudencia arbitral" para definir sus contornos. Véase por ejemplo, los libros de Schreuer, The ICSID Convention: A Commentary, 2001; Rubino-Sammartano, International arbitration law and practice, 2001; Douglas, The International Law of Investment Claims, cit.; Redfern \& Hunter, Law and practice of international commercial arbitration, op. cit. 
La práctica demuestra que el precedente, si bien no es obligatorio, tiene un importante valor normativo. Los precedentes arbitrales son usados por las partes para fundar sus pretensiones jurídicas en el proceso legal y absorben una buena parte de las discusiones y de la motivación del laudo arbitral. "Descubrir, enumerar, distinguir precedentes no es una tarea inútil, y no se llevaría a cabo si no entrara sistemáticamente en la decisión de los casos". ${ }^{162} \mathrm{Si}$ bien la misión del árbitro es la de solucionar una controversia especifica sobre la interpretación o ejecución de las obligaciones de un tratado, contrato o ley específica, dicha aplicación no es una actividad mecánica. El árbitro tiene un poder de interpretación que permite clarificar, colmar lagunas, adaptar la regla a los tiempos actuales y coordinar la esfera de aplicación de cada uno de los órdenes jurídicos que aplica. Es justamente este poder el que permite el desarrollo de las soluciones consensuadas. Ellas tienen su origen y adquieren su generalidad de la aceptación que otros árbitros hacen de la solución.

La existencia de soluciones consistentes en la forma de aplicar e interpretar las normas que el árbitro aplica plantea interrogantes. ¿Qué rol juegan estas soluciones?, ¿son legítimas?, ¿son deseadas?, ¿cuál es su estatus? Estas son algunas de las preguntas que surgen respecto de estas soluciones. Las respuestas a estas preguntas requieren un estudio profundo del arbitraje de inversiones, así como de su interacción con otros órdenes jurídicos y su recepción por un público más amplio. Un estudio en tal sentido, no sólo permitirá entender mejor el arbitraje de inversiones sino que fomentará el desempeño responsable de la misión de los árbitros.

\section{BIBLIOGRAFÍA}

\section{Libros}

Aguiló Regla, J., Teoría general de las fuentes del derecho: (y del orden jurídico). Barcelona, 2000.

ANCEL, P. et al., Les divergences de jurisprudence, Université de SaintEtienne, 2003.

Austin, J., The province of jurisprudence determined, J. Murray, 1861.

162 Landes and Posner, "Legal Precedent”, cit., p. 252. 
Bentham, J., Theory of legislation, K. Paul, Trench, 1908.

Bonnecase, J., Introduction à l'étude du droit, 3a. ed., París, Sirey, 1939.

BORN, G., International Commercial Arbitration, Kluwer Law International, 2009.

Cardozo, B. N., The Nature of the Judicial Process, Read Books, 1921.

Clay, T. L'arbitre, Nouvelle Bibliothèque de Thèses, París, Dalloz, 2001.

Coste-Floret, A., Les problèmes fondamentaux du droit, París, Dalloz, 1946.

DAVID, R., L’arbitrage dans le commerce international, Económica, 1982.

Douglas, Z., The International Law of Investment Claims, Cambridge University Press, 2009.

FISH, S., There's No Such Thing as Free Speech. And it's a Good Thing Too. Oxford University Press, 1994.

FOUCHARD et al., On International Commercial Arbitration, Kluwer Law International, 1999.

Gaillard, E., Aspects philosophiques du droit de l'arbitrage international, Martinus Nijhoff, 2008.

Gaillard, E. y Banifatemi, Y., Precedent in International Arbitration, Juris Net Llc, 2008.

GENY, F., Méthode d'interprétation et sources en droit privé positif: essai critique, 2a. ed., vol. II., Librairie générale de droit et de jurisprudence, 1995.

GRAY, J. C., The nature and sources of the law, The Macmillan Company, 1921.

Hart, H.L.A., The concept of law, Clarendon Press Oxford, 1994.

HISTORY of the ICSID Convention. Documents concerning the origin and the formulation of the Convention on the Settlement of Investment Disputes between States and Nationals of other States, vol. II., Washington, D. C., 1968, Reprint, 2001.

Holmes, O.W., The common law, Dover Pubns, 1991.

KASSIS, A., L'autonomie de l'arbitrage commercial international, París, L'Harmattan, 2005.

Kennedy, D., A Critique of Adjudication (fin de siècle), Cambridge, Massachusetts, London, Harvard University Press, 1998.

Kunn, T. S., The Structure of Scientific Revolutions, Chicago and London, University of Chicago Press, 1966. 
MCNaIR, S. A. D., The Development of International Justice, 1954.

Montesquieu, C.-L.d.S.d., De l'esprit des lois, París, Garnier, 1962.

Murphy, F. W., Courts, Judges, and Politics, 5a. ed., 2002.

Perelman, C., La nouvelle rhétorique.Traité de l'argumentation, Editions de l'Université de Bruxelles, 1992.

Planiol, M., Traité élémentaire du droit civil conforme au programme officiel de la faculté de droit, vol. 1, 1899.

Posner, R. A., How Judges Think, London, Harvard University Press, 2008.

Pound, R., The spirit of the common law, Transaction Pub, 1998.

PUIG BRUTAU J. et al., La jurisprudencia como fuente de derecho. Interpretación creadora y arbitrio judicial, Edición Homenaje a D José Puig Brutau, 2a. ed., Bosch, 2006.

REDFERN A. y Hunter, Law and practice of international commercial arbitration. Sweet \& Maxwell, 2004.

Ross, A., On Law and Justice, The Lawbook Exchange, 2004.

Rubino-Sammartano, M. International Arbitration Law and Practice, Kluwer Law Intl, 2001.

Schreuer, C., The ICSID Convention: A Commentary. Cambridge: Cambridge University Press, 2001.

Wasserstrom, R., Judicial Decision Towards a Theory of Legal Justification. Stanford Univ Pr, 1961.

Zenati, F., La jurisprudence, Méthodes du droit, París, Dalloz, 1991.

2. Capítulos de libros

Allard, J., "Le dialogue des juges dans la mondialisation", Le dialogue des juges Actes du colloque organisé le 28 avril 2006 à l'Université de Bruxelles, 2007, 77.

BIANCHI, A., "Looking ahead: international law's main challenges", in Armstrong, D. (ed.), Routledge Handbook of International Law, 2009.

BJorklund, A. K., "Investment Treaty Arbitral Decisions as Jurisprudence Constante”, En Picker et al. (eds.), International Economic Law: The State and Future of the Discipline, 2008. 
FORTEAU, M., "Le juge CIRDI envisagé du point de vue de son office: juge interne, juge international, ou l'un et l'autre à la fois?", Liber Amicorum Jean-Pierre Cot, Le procès international, 2009, 95.

Giovannini, T., "International Arbitration and Jura Novit CuriaTowards Harmonization”, en FERNÁNDEZ et al. (eds.), Liber Amicorum Bernardo Cremades, 2010, 495.

GRZEGORCZYK, C., "Jurisprudence: phénomène judiciaire, science ou méthode?", en Terré, F. (ed), La jurisprudence Archives de Philosophie du Droit, 1985, 35-52.

LEBEN, C., "Quelques réflexions théoriques à propos des contrats d'Etat", Souveraineté étatique et marchés internationaux à la fin du 20ème siècle A propos de 30 ans de recherche du CREDIMI Mélanges en l'honneur de Philippe Kahn (2000).

ManN, F. A., "Lex Facit Arbitrum”, International Arbitration Liber Amicorum for Martin Domke, 1986.

MAYER, P. , "La règle morale dans l'arbitrage international”, Etudes offertes à Pierre Bellet, 1991.

, "The Trend Towards Delocalisation in the Last 100 years", The Internationalisation of Interantional Arbitration The LCIA Centenary Conferenc, 1995.

Paulsson, J., "International Arbitration and the Generation of Legal Norms: Treaty Arbitration and International Law", en V. D. BERG (ed.), International Arbitration 2006: Back to Basics, 2007, 879-889.

, "The Role of Precedent in Investment Arbitration", en YANNA-

CA-SMAll (ed.), Arbitration Under International Investment Agreements A Guide to the Key Issues, 2010, 699.

REINISCH, A., "The Role of Precedent in ICSID Arbitration”, en Klausegger and Klein (eds), Austrian Arbitration Yearbook (2008).

SAlaCUSE, J. W., "Towards a Global Treaty on Foreign Investment: The Search for a Grand Bargain”, en HorN (ed.), Arbitrating Foreign Investment Disputes, 2004, 61.

Schreuer, C. y Weiniger M., "A Doctrine of Precedent?", in Muchlinski et al. (eds.), The Oxford Handbook of International Investment Law, 2008.

StOnE, J., "Interpretations of Modern Legal Philosophies". 
Von Mehren, A., "Limitations to Party Choice of the Governing Law: Do They Exist for International Commercial Arbitration?", The Mortimer and Raymond Sackler Institute of Advanced Studies, 1986.

Walde, T., "Confidential Awards as Precedent in Arbitration. Dynamics and Implication of Award Publication", en Gailllard, E. y BANIFATEMI, Y. (eds.), Precedent in International Arbitration, 2007, 113-135.

, “The Specific Nature of Investment Arbitration”, en K. Wälde (ed), Les aspects nouveaux du droit des investissements internationaux/New Aspects of International Investment Law, 2007.

\section{Artículos}

Bentolila, D., "'Shareholders' action to claim for indirect damages”, 2 (1) Trade, Law \& Development, 2010, 87.

Cheng, T.-H., "Precedent and Control in Investment Treaty Arbitration”, 30 Fordham Int'L L J, 2006-2007 , 1014.

Cole, T., "Authority and Contemporary International Arbitration", 70 Louisiana Law Review, 2010, 802.

Commission, J. P., "Precedent in Investment Treaty Arbitration. A Citation Analysis of a Developing Jurisprudence”, 24 (2) Journal of International Arbitration, 2007, 129.

CRAWFORD, J., "Continuity and Discontinuity in International Dispute Settlement: An Inaugural Lecture”, 1 (1) Journal of International Dispute Settlement, 2010, 3.

Cuniberti, G., "Beyond Contract-The Case for Default Arbitration in International Commercial Disputes”, 32 Fordham Int'l LJ, 2008.

Di PIETRO, D. , "The Use of Precedents in ICSID Arbitration: Regularity or Certainty?”, (3) International Arbitration Law Review, 2007, 92.

Douglas, Z., "The Hybrid Foundations of Investment Treaty Arbitration”, 74 BYIL, 2004, 151.

FranCK, S. D., "The Legitimacy Crisis in Investment Treaty Arbitration: Privatizing Public International Law Through Inconsistent Decisions", 73 Fordham Law Review, 2005.

Gerhardt, M. J., “The Limited Path Dependency of Precedent”, 7 U Pa J Const L, 2004-2005, 903. 
Gibson, C. S. y Drahozal, C. R., "Iran-United States Claims Tribunal Precedent in Investor-State Arbitration”, 23 (6) Journal of International Arbitration, 2006, 521.

GOldman, B., "Les conflits de lois dans l'arbitrage international de droit privé”, 109 RCADI, 1963, 17.

JACQUET, J.-M., “Avons-nous besoin de jurisprudence arbitrale?”,

Revue de l'arbitrage, 2010, 445.

Kaufmann-Kohler, G., "Arbitral Precedent: Dream, Necessity or Excuse?”, 23 (3) Arbitration International, 2007, 357

Kennedy, D., "Critical Theory, Structuralism and Contemporary Legal Scholarship”, New Eng L Rev, 1985-6, 209.

, "One, Two, Three Many Legal Orders: Legal Pluralism and the

Cosmopolitan Dream”, 31 New York University Review of Law and Social Change, 2007, 641.

Landes, W. M. y Posner, R. A., "Legal Precedent: A Theoretical and Empirical Analysis", 19 Journal of Law and Economics, 1976, 249.

PAULSSON, J., "Arbitration without privity”, 10 (2) ICSID Review, 1995. Popelier, P., "Five Paradoxes on Legal Certainty and the Law Maker", II (1) Legisprudence, 47.

, "Legal Certainty and Principles of Proper Law Making", 2

European Journal of Law Reform, 2000, 321.

Posner, R. A., "Past-Dependency, Pragmatism, and Critique of History in Adjudication and Legal Scholarship”, 67 (3) U Chi L Rev, 2000, 573.

SCHREUER C., "Diversity and Harmonization of Treaty Interpretation in Investment Arbitration", 3 (2) Transnational Dispute Management, 2006.

, "Fair and equitable treatment in arbitral practice", 6 (3) The Journal of World Investment \& Trade, 2005, 359.

Sprecher, R. A., "The Development of the Doctrine of Stare Decisis and the Extent to Which It Should be Applied”, 31 ABAJ, 1945, 468. STERN, B. "Le consentement à l'arbitrage CIRDI en matière d'investissement international: que disent les travaux préparatoires”, Mélanges Ph KAHN.

Thompson A., "Applying Rational Choice Theory to International Law:

The Promise and Pitfalls", XXXI Journal of Legal Studies, 2002, S285. 
TunC A., "Jurisprudence”, 9 Encyclopaedia Universalis.

VADI, V. S., “Towards Arbitral Path Coherence \& Judicial. Borrowing: Persuasive Precedent in Investment Arbitration”, 5 (3) Transnational Dispute Management, 2008.

Walsh, T. W., "Substantive Review of ICSID Awards: Is the Desire for Accuracy Sufficient to Compromise Finality", 24 Berkeley Journal of International Law, 2006. 